UNIVERSIDADE DE SÃO PAULO

FACULDADE DE MEDICINA DE RIBEIRÃO PRETO

DEPARTAMENTO DE MEDICINA SOCIAL

FELIPE DIAS CARVALHO

\title{
Avaliação econômica do impacto da atividade de Atenção Farmacêutica na assistência à saúde: aspectos metodológicos
}




\author{
UNIVERSIDADE DE SÃO PAULO \\ FACULDADE DE MEDICINA DE RIBEIRÃO PRETO \\ DEPARTAMENTO DE MEDICINA SOCIAL
}

\title{
FELIPE DIAS CARVALHO
}

Avaliação econômica do impacto da atividade de Atenção Farmacêutica na assistência à saúde: aspectos metodológicos

Ribeirão Preto 


\section{FELIPE DIAS CARVALHO}

\section{Avaliação econômica do impacto da atividade de Atenção Farmacêutica na assistência à saúde: aspectos metodológicos}

Dissertação de mestrado apresentada ao programa de pós-graduação em Ciências Médicas da Faculdade de Medicina de Ribeirão Preto da Universidade de São Paulo, como parte das exigências para obtenção do título de mestre.

Área de Concentração: Saúde na Comunidade Orientador: Prof. Dr. Juan Stuardo Yazlle Rocha

Ribeirão Preto 
Autorizo a reprodução e divulgação total ou parcial deste trabalho, por qualquer meio convencional ou eletrônico, para fins de estudo e pesquisa, desde que citada a fonte.

Carvalho, Felipe Dias.

Avaliação econômica do impacto da atividade de Atenção Farmacêutica na assistência à saúde: aspectos metodológicos / Felipe Dias Carvalho; orientador: Prof. Dr. Juan Stuardo Yazlle Rocha - Ribeirão Preto - SP, 2007. $103 \mathrm{f}$.

Dissertação (Mestrado - Programa de Pós-Graduação em Ciências Médicas. Área de concentração: Saúde na Comunidade) - Faculdade de Medicina de Ribeirão Preto da Universidade de São Paulo.

1. Atenção Farmacêutica - Uso Racional de Medicamentos. 2. Economia da Saúde - Avaliação Econômica de Serviços de Atenção Farmacêutica. 


\section{Felipe Dias Carvalho}

\section{Avaliação econômica do impacto da atividade de Atenção Farmacêutica na assistência à saúde: aspectos metodológicos}

Dissertação de mestrado apresentada ao programa de pós-graduação em Ciências Médicas da Faculdade de Medicina de Ribeirão Preto da Universidade de São Paulo, como parte das exigências para obtenção do título de mestre.

Área de concentração: Saúde na Comunidade

Trabalho aprovado pela Banca Examinadora em /2007.

Prof. Dr. Juan Stuardo Yazlle Rocha (Orientador)

Instituição: FMRP-USP

Assinatura:

Prof. Dr. Leonardo Régis Leira Pereira

Instituição: FCFRP-USP

Assinatura:

Prof. Dr. Walter Belluzzo Júnior

Instituição: FEARP-USP

Assinatura: 
A Maria Auxiliadora Dias, minha mãe querida, sempre forte e perseverante, pelo apoio e pelo exemplo de dedicação e caráter.

A Helaine Carneiro Capucho, minha noiva, companheira nos momentos mais importantes, pelo incentivo, apoio, colaboração e conforto.

Eu as amo. 


\section{AGRADECIMENTOS}

Enfim, chega ao final mais um desafio que me dispus a enfrentar. Nessa etapa, muitos foram os que colaboraram para que eu obtivesse o êxito esperado. Gostaria de expressar, aqui, minha gratidão e dizer o quanto vocês são importantes para mim. Provavelmente tenha me esquecido de citar alguém, mas saibam que serei eternamente grato a todos vocês.

À Deus pelas oportunidades, pela vida, pelos verdadeiros amigos e pela família que tenho, razões e incentivo para viver. Apesar de distantes tenho vocês sempre comigo.

À minha mãe, Dodôra, pelo carinho e amor, pelos estudos, pela criação, pela educação e por todos os esforços para propiciar que eu chegasse até aqui.

À Helaine, meu amor, pela paciência, compreensão e dedicação, sempre compartilhando sonhos e vivências.

À Luciana e Eduardo, minha irmã e meu cunhado, amado casal que sempre me apoiou e ajudou.

À minha avó, Leontina, pelas orações e bênçãos, sempre alegre e vibrante, um exemplo de amor à família, amada por todos nós.

À Laís, minha sobrinha, pelo carinho, alegria e bom humor que irradia a toda família.

Ao Gabriel, meu sobrinho, outro "anjinho" que chegou para nos alegrar ainda mais.

Ao Capucho, meu sogro, pelo incentivo e pela torcida. 
Ao Prof. Dr. Juan Stuardo Yazlle Rocha pela orientação, pelos conhecimentos transmitidos e pela confiança em mim depositada.

À Prof. Dra. Aldaísa Casanho Forster pelo auxílio durante a elaboração do projeto de mestrado e pelo incentivo transmitido até hoje.

Aos professores do Departamento de Medicina Social da FMRP-USP pelos conhecimentos compartilhados e pelos bons momentos vividos.

Aos funcionários do Departamento de Medicina Social da FMRP-USP (Carolina Cecília Bruno Batista, Gilmar Mazzer, Mônica Knack, Regina Helena Greggi Alcântara e Solange Pedersoli) pela paciência, pela boa convivência e pela ajuda constante durante todo o curso.

Aos professores Leonardo Régis Leira Pereira (FCFRP-USP), Walter Belluzo Júnior (FEARP-USP) e Aldaísa Casanho Forster (FMRP-USP) pelas importantes contribuições oferecidas durante o exame de qualificação.

Aos colegas de mestrado pela convivência e pela troca de conhecimentos, o que tornou menos árdua a tarefa de transpor as disciplinas do curso.

Aos colegas de trabalho da Divisão de Assistência Farmacêutica do HCFMRP-USP pelo suporte nas atividades laborais, permitindo que eu adequasse meus horários de trabalho para cumprir as disciplinas do curso.

À Universidade de São Paulo pelo ensino gratuito e de excelente qualidade. 
“... Mas é preciso ter força, é preciso ter raça É preciso ter gana sempre... ... Mas é preciso ter manha, é preciso ter graça É preciso ter sonho sempre Quem traz na pele essa marca Possui a estranha mania de ter fé na vida." 


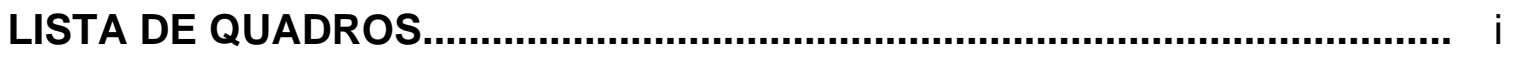

LISTA DE ABREVIATURAS E SIGLAS..................................................... ii

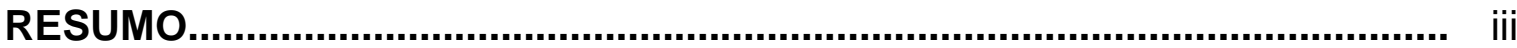

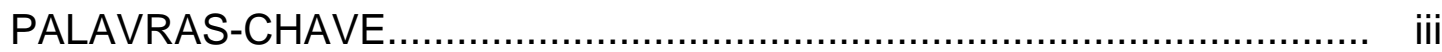

ABSTRACT

KEY-WORDS

1. INTRODUÇÃO

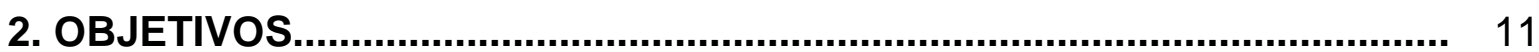

2.1. OBJETIVO GERAL....................................................................... 11

2.2. OBJETIVOS ESPECÍFICOS..................................................... 11

3. MÉTODOS

4. RESULTADOS E DISCUSSÃO................................................................. 19

4.1. ATENÇÃO FARMACÊUTICA........................................................ 20

4.2. AVALIAÇÃO EM SAÚDE............................................................. 36

4.3. ECONOMIA DA SAÚDE............................................................... 44

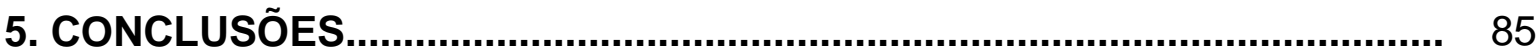

REFERÊNCIAS BIBLIOGRÁFICAS........................................................... 87 


\section{LISTA DE QUADROS}

Quadro 1 - Codificação de temas e relação de palavras-chave utilizadas na pesquisa.

Quadro 2 - Classificação de problemas farmacoterapêuticos, segundo o grupo de Minnesota......

Quadro 3 - Classificação de problemas relacionados aos medicamentos, baseada nas três necessidades fundamentais da farmacoterapia, segundo o Primeiro Consenso de Granada.

Quadro 4 - Vantagens e limitações do método de estudo experimental

Quadro 5 - Vantagens e limitações do método de estudo transversal.

Quadro 6 - Vantagens e limitações do método de estudo tipo coorte

Quadro 7 - Vantagens e limitações do método de estudo tipo caso-controle... 76 


\section{LISTA DE ABREVIATURAS E SIGLAS}

ABC - Custeio baseado em atividades.

ACM - Análise tipo custo-minimização.

ACE - Análise tipo custo-efetividade.

ACB - Análise tipo custo-benefício.

ACU - Análise tipo custo-utilidade.

ASHP - Associação Americana de Farmacêuticos de Hospital e Sistemas de Saúde.

ATENFAR - Atenção farmacêutica.

ATS - Avaliação de tecnologia de saúde.

AVAQ - Anos de vida ajustados pela qualidade.

ECHO model - Economic, Clinical and Humanistic Outcomes model.

EUA - Estados Unidos da América.

ex.: - Exemplo.

OMS - Organização Mundial de Saúde.

OPAS - Organização Panamericana de Saúde.

PIB - Produto interno bruto.

PRM - Problema relacionado com medicamento.

PWDT - Pharmacist's Workup of Drug Therapy.

RAM - Reação adversa ao medicamento.

SUS - Sistema Único de Saúde.

TOM - Therapeutic Outcomes Monitoring.

TOMCOR - Therapeutic Outcomes Monitoring in Coronary Patients.

UBS - Unidade básica de saúde

URM - Uso racional de medicamentos. 


\section{RESUMO}

CARVALHO, F. D.. Avaliação econômica do impacto da atividade de Atenção Farmacêutica na assistência à saúde: aspectos metodológicos. 2007. 103 f. Dissertação (Mestrado) - Faculdade de Medicina de Ribeirão Preto, Universidade de São Paulo, Ribeirão Preto, 2007.

A atenção farmacêutica (ATENFAR) é uma nova prática clínica, inerente ao profissional farmacêutico, que tem como principais objetivos a prevenção de doenças, a promoção e a recuperação da saúde de usuários de serviços sanitários, através do fomento ao uso racional de medicamentos. Vários estudos realizados no Brasil e no exterior mostram que a atividade de ATENFAR pode propiciar muitos benefícios aos tratamentos de saúde que fazem uso de farmacoterapia, resultando no aumento da efetividade do tratamento e na melhoria da qualidade de vida dos pacientes. Além disso, alguns estudos mostram que a ATENFAR exerce influência sobre os custos assistenciais, sendo esta informação de grande importância para que se discuta a inserção desta prática em programas de saúde coletiva. Devido à escassez de estudos econômicos sobre serviços de ATENFAR, este trabalho visou, através de pesquisa bibliográfica, levantar informações acerca dos temas Economia da Saúde, Atenção Farmacêutica e Avaliação em Saúde e discutir criticamente a aplicabilidade e adequação dessas informações aos referidos estudos.

A análise das publicações encontradas através da revisão bibliográfica realizada permitiu concluir que:

- As análises econômicas tipo custo-minimização, tipo custo-efetividade, tipo custo-utilidade e tipo custo-benefício são aplicáveis a serviços de ATENFAR;

- Os custos relativos aos salários dos farmacêuticos, dos auxiliares e dos demais membros da equipe de saúde; ao transporte do paciente ou da equipe de saúde; aos materiais de consumo; aos medicamentos; às internações hospitalares; aos atendimentos médicos de urgência; às sensações de dor, de tristeza, de mal estar; aos dias de trabalho perdidos; à necessidade de um cuidador; ao aluguel do espaço destinado ao serviço; são custos que devem ser levantados em uma avaliação econômica de serviços de ATENFAR;

- A melhoria em parâmetros clínicos e na qualidade de vida de pacientes atendidos por serviços de ATENFAR e a economia de recursos financeiros, são possíveis resultados gerados por esses serviços;

- As análises econômicas de serviços de ATENFAR podem ser realizadas sob a perspectiva do paciente, da instituição de saúde, do plano de saúde, do sistema de saúde, da sociedade ou de qualquer outro agente que tenha interesse em realizar uma avaliação econômica de tais serviços;

- Os modelos de estudos epidemiológicos mais indicados para serem utilizados em análises econômicas de serviços de ATENFAR são o modelo experimental e 0 modelo observacional longitudinal tipo coorte prospectivo.

Palavras-chave: Atenção Farmacêutica, Economia da Saúde, Avaliação em Saúde, Problemas Farmacoterapêuticos, Uso Racional de Medicamentos. 


\begin{abstract}
CARVALHO, F. D.. Economic evaluation of Pharmaceutical Care activity impact in health assistance: methodological aspects. 2007. 103 f. Dissertation (Master) Faculdade de Medicina de Ribeirão Preto, Universidade de São Paulo, Ribeirão Preto, 2007.
\end{abstract}

The pharmaceutical care is a new practical clinic, inherent to the pharmaceutical professional, who has as main objectives the prevention of illnesses, the promotion and recovery of health of sanitary services users, through the fomentation of rational drug use. Several studies accomplished in Brazil and the exterior show that the pharmaceutical care activity can propitiate many benefits to the health treatments which use the pharmacotherapy, resulting in the increase of treatment effectiveness and in the improvement of life quality of patients. Moreover, some studies show that the pharmaceutical care exerts influence on the assistance costs, being this information of great importance to discuss the insert of this practical in collective health programs. Due to scarcity of economic studies on pharmaceutical care services, the present work aimed at, through bibliographical research, raise information about the topics Health Economics, Pharmaceutical Care and Health Evaluation and to critically discuss the applicability and adequacy of this information to the related studies.

The analysis of publications found by means of bibliographic revision lead to the conclusion that:

- The economic analyses type cost-minimization, type cost-effectiveness, type costutility and type cost-benefit are applicable to pharmaceutical care services;

- The cost concerning to the wages of the pharmacist, the assistant and others members of the health team; to the patients or health team transport; to the consumption materials; to medicines; to the hospital internments; to the medical attends of urgency; to the sensations of pain, sadness and badly being; to the lost days of work; to the necessity of attendant; to the rent of the space destined to the service; they are costs that must be raised in a economic evaluation of pharmaceutical care services;

- The improvement in clinical parameters and the life quality of patients taken care for pharmaceutical care services and the economy of financial resources are possible results from these services;

- The system of assumption of costs by absorption or traditional and the system of activity based costs (ABC) are the most indicated to be established in health units that offer pharmaceutical care services;

- The economic analyses of pharmaceutical care services might be carried through under the patient perspective, the health institution, the health plan, the health system, the society or any other agent who has interest in realize an economic evaluation of such services;

- The most indicated models of epidemiological studies to be used in economic analyses of pharmaceutical care services are the experimental model and the longitudinal observational model type prospective cohort.

Keywords: Pharmaceutical Care, Health Economics, Health Evaluation, MedicineRelated Problems, Rational Drug Use. 


\section{INTRODUÇÃO}

As estreitas relações entre a economia e a saúde são reconhecidas em todo o mundo há mais de trinta anos. A saúde, objetivo de todas as pessoas depende, em grande parte, da distribuição dos recursos econômicos (BASSKIN, 1998).

Nas últimas décadas, o aumento da demanda por serviços de saúde e a elevação nos custos assistenciais têm contribuído para que o atendimento à população se contextualize num déficit tanto quantitativo como qualitativo, preocupando não só os gestores, que devem eleger prioridades e buscar estratégias para melhorar a aplicação dos recursos financeiros destinados ao setor, mas também os prestadores e usuários dessa assistência (MÉDICI, 1990; SILVA; FERNANDES; GONÇALVES, 1994; MOSEGUI, 2002).

A escassez de recursos para a saúde restringe a possibilidade de ampla distribuição de bens e serviços públicos e, portanto, exige uma série de decisões alocativas que visem maximizar os resultados das ações financiadas por esses recursos. Em um país como o Brasil, onde há pobreza massiva, grande demanda por cuidados sanitários e a impossibilidade de vasta parcela da população obter serviços fora do sistema público, a responsabilidade dessas decisões é extremamente grande. Em realidades de profunda desigualdade social, considerar os custos das atividades relacionadas com a saúde pode assumir um caráter não ético. No entanto, a complexidade crescente dos sistemas de saúde e o reconhecimento de que as necessidades de saúde são inesgotáveis, exigem que se avalie a relação entre os recursos utilizados e os resultados da prestação de serviços ou de atividades desenvolvidas (COUTTOLENC, 2001; CASTRO, 2002; TANAKA; MELO, 2004). 
A aplicação de critérios econômicos para auxiliar a tomada de decisões no setor saúde não entra em conflito com a ética. Ao contrário, essa prática considera as restrições determinadas pela limitação de recursos e persegue a eficiência dos sistemas, programas, serviços e ações de saúde, levando em consideração os princípios de universalidade, eqüidade e integralidade, o que equivale a não se conformar com níveis de saúde, de bem-estar e de acesso inferiores aos que, na verdade, poderiam ser conseguidos com a utilização de estratégias econômicas para a aplicação dos recursos destinados ao setor. Nesse sentido, pode-se afirmar que, antiético é ignorar uma realidade incômoda da saúde coletiva, a escassez de recursos, quando dela se desprende um possível prejuízo para a sociedade (DEL CASTILHO, 1995; DEL NERO, 1995; SAES, 2000).

O uso de ferramentas de avaliação econômica na área da saúde é um importante artifício que, quando empregado corretamente, auxilia os gestores a estabelecerem prioridades entre as diferentes alternativas que concorrem pelos mesmos recursos, na busca de aumentar a eficiência dos sistemas de saúde.

Uma atividade que vem se mostrando como alternativa para aumentar a eficiência de sistemas de saúde é a chamada Atenção Farmacêutica (ATENFAR). Há evidências que esta atividade aumenta a efetividade de tratamentos sanitários e melhora a qualidade de vida dos pacientes que dela fazem uso, além de reduzir os custos desses tratamentos. Entretanto tais evidências carecem de comprovação, o que deve ser feito com o auxílio de um instrumento de avaliação econômica desenvolvido especificamente para avaliar a ATENFAR (PLUMRIDGE; WOJNARHORTON, 1998; SOLOMON et al., 1998; WEIDLE et al., 1999).

O exercício da ATENFAR busca combater o importante problema social da morbimortalidade relacionada aos medicamentos, empregando um processo de 
cuidado centrado no paciente e uma responsabilidade profissional claramente definida. A prevalência e os custos dessa morbimortalidade são de grande relevância para os gestores de sistemas de saúde, pacientes e a sociedade como um todo (LEE; RAY, 1993; POSEY, 1997; MALHOTRA; JAIN; PANDHI, 2001; CIPOLLE; STRAND; MORLEY, 2002).

A morbimortalidade relacionada aos medicamentos advém dos problemas relacionados com medicamentos $(\mathrm{PRM})$, os quais afetam grande parcela da população que faz uso de terapia medicamentosa. Diversas publicações têm mostrado que os PRM, além de influenciar negativamente na evolução clínica dos pacientes, são responsáveis por um número considerável de hospitalizações e mortes a cada ano, gerando um aumento significativo dos custos dos sistemas de saúde (EINARSON, 1993; SMITH et al., 1996; LAZAROU; POMERANZ; COREY, 1998; PIRMOHAMED et al., 1998; MOORE et al., 1998; DURÁN; ROMERO; FAUS, 1999; AJAYI; SUN; PERRY, 2000; WHITE; ARAKELIAN; ROH, 1999; BILLUPS; MALONE; CARTER, 2000; BORDET et al., 2001; PATEL; ZED, 2002; LLIMÓS; FAUS, 2003; VIEIRA, 2007).

Nos Estados Unidos da América (EUA), nos últimos anos, os PRM foram responsáveis por cerca de $10 \%$ das internações hospitalares e os custos com as doenças associadas aos medicamentos triplicaram, ultrapassando os US\$150 bilhões por ano (ANDERSON; GANGS, 1997; ERWIN, 1999; CERULLI, 2001; CIPOLLE; STRAND; MORLEY, 2002).

Uma revisão de estudos publicados na Austrália, entre os anos de 1988 a 1996, demonstrou que as taxas de internações relacionadas aos medicamentos foram $2 \%$ a $4 \%$ do total de internações, $6 \%$ a $9 \%$ das admissões em emergências, 
12\% das admissões em unidades de clínica médica e 15\% a 22\% das admissões em geriatria (ROUGHEAD et al., 1998).

Em 2002, Winterstein et al. publicaram uma metanálise de artigos sobre internações hospitalares relacionadas aos medicamentos. Segundo os resultados, as taxas de prevalência variaram de 3\% a $9 \%$ das internações. Os autores ressaltaram que mais de $50 \%$ dessas internações poderiam ter sido prevenidas.

A redução da morbimortalidade prevenível relacionada aos medicamentos tem um impacto positivo na qualidade de vida dos pacientes, na confiabilidade do sistema de saúde e na eficiência no uso de recursos. As principais causas dessa morbimortalidade são prescrições inadequadas, reações adversas aos medicamentos (RAM), não adesão ao tratamento, superdosagem ou subdosagem, falta da farmacoterapia necessária, inadequado seguimento de sinais e sintomas, e erros de medicação (HENNESSY, 2000; MORRIS et al., 2002).

Segundo Hepler (2000), a morbimortalidade prevenível relacionada aos medicamentos é um problema para muitos sistemas de saúde, e, por isso, os resultados inadequados da farmacoterapia devem ser prevenidos sob um ponto de vista clínico e humanitário. Além disso, os recursos financeiros gastos com a morbimortalidade prevenível relacionada aos medicamentos são suficientes para evitar o problema e permitir outras intervenções no sistema de saúde, tornando-o mais eficiente.

Nos Estados Unidos, lesões não intencionais associadas à farmacoterapia têm afetado 2,5 milhões de pessoas por ano e o custo relacionado à hospitalização dos pacientes devido ao efeito adverso chega a atingir, anualmente, US\$177 bilhões (CERULLI, 2001). 
No Brasil, há uma carência quase absoluta de estudos independentes sobre morbimortalidade relacionada aos medicamentos, além da omissão do poder público no tratamento da questão (LYRA JÚNIOR, 2005). Entretanto, alguns levantamentos afirmam que os medicamentos ocupam a primeira posição entre os causadores de intoxicações, desde 1996 (SINITOX, 2000). Esta classificação, além de preocupante, no que se refere à necessidade de adoção de medidas que previnam os agravos à saúde da população, gera reflexos sobre os custos inerentes às ações desenvolvidas no Sistema Único de Saúde (SUS) (OPAS, 2002b).

O envolvimento do farmacêutico no processo de atenção à saúde é de fundamental importância para a prevenção dos danos causados pelo uso irracional de medicamentos. Nesse processo, os esforços para a readequação de atividades e práticas farmacêuticas, objetivando o uso racional dos medicamentos (URM), são essenciais, visto que, no mundo ocidental contemporâneo, no qual o modelo de assistência à saúde é excessivamente "medicalizado" e "mercantilizado", cabe aos medicamentos um espaço importante no processo saúde/doença, sendo praticamente impossível pensar na prática médica ou na relação médico/paciente sem a presença desses produtos. Nesta sociedade os fármacos constituem o "arsenal terapêutico" mais utilizado (BATES, 1995; LIPTON et al., 1995; SOARES, 1998).

A primeira investigação sobre o impacto das ações de ATENFAR na sociedade foi realizada nos Estados Unidos, utilizando os dados do Projeto Minnesota de Atenção Farmacêutica (Minnesota Pharmaceutical Care Project). Strand, Cipolle e Morley (1988), idealizadores desse projeto, avaliaram os serviços clínicos prestados pelo farmacêutico sob a ótica das análises tipo custo-benefício e tipo custo-efetividade, relatando que ainda não havia um padrão para avaliação dos 
resultados das atividades clínicas dos farmacêuticos, o que era comum para médicos e enfermeiros. Os resultados da referida investigação demonstraram que, após um ano, aumentou o número de pacientes que alcançaram resultado terapêutico satisfatório e que a resolução dos PRM reduziu a complexidade da demanda farmacoterápica, gerando uma relação custo-resultado aparentemente favorável (TOMECHKO; MORLEY, STRAND, 1996; STRAND, 1997; CIPOLLE; STRAND; MORLEY, 2002).

Salvia e colaboradores (1999) relataram os resultados da implantação de um programa de ATENFAR em um hospital espanhol. As ações foram desenvolvidas através da identificação, prevenção e resolução de PRM. Nesse estudo, os autores concluíram que a intervenção farmacêutica melhora os resultados clínicos e exerce influências nos custos assistenciais. Outro estudo europeu avaliou a provisão de ATENFAR a idosos, através de uma pesquisa multicêntrica, verificando a redução dos custos de tratamento e aumento da qualidade de vida dos pacientes. Os pacientes do grupo intervenção manifestaram melhor controle de sua doença e alto nível de satisfação. Nesse estudo, a opinião de médicos e farmacêuticos foi favorável à ATENFAR (BERNSTEN et al., 2001).

Um trabalho desenvolvido pela Universidade do Tennessee e pelo Departamento Americano de Assuntos da Terceira Idade, visou avaliar o impacto clínico, econômico e humanístico da provisão de atenção farmacêutica, em pacientes ambulatoriais portadores de hipertensão arterial e doença pulmonar obstrutiva crônica. No grupo intervenção obteve-se melhor adesão à terapia medicamentosa e melhor conhecimento da doença e do tratamento, além de uma menor utilização de serviços sanitários e hospitalizações, o que poderia aumentar os custos dos tratamentos (GOURLEY et al., 1998). 
De acordo com os resultados do estudo de Phillips e Carr-Lopez (1990), a prestação de ATENFAR a pacientes idosos aumenta a adesão a seus regimes terapêuticos, podendo promover redução de custos hospitalares, ao reduzir o número de prescrições, de internações e de medicamentos associados a reações adversas aos medicamentos.

Lyra Júnior (2005), realizou um estudo no Brasil, também com idosos, constatando que as intervenções educativas otimizaram a utilização dos medicamentos, resultando na resolução e prevenção de aproximadamente $70 \%$ dos PRM identificados. Além disso, o autor constatou que o impacto das intervenções farmacêuticas resultou em aumento da efetividade do tratamento dos idosos hipertensos e que os resultados humanísticos do serviço de atenção farmacêutica foram satisfatórios, pois os idosos demonstraram melhora significativa em seus índices de qualidade de vida após a utilização desse serviço. Os idosos aprovaram, com alto grau de satisfação, o serviço de ATENFAR e a atuação do farmacêuticopesquisador.

Em conseqüência dos resultados descritos pelo autor, houve uma redução marcante nos relatos dos idosos quanto às internações freqüentes e à procura dos serviços de emergência, comuns antes do início do programa, o que pode ter causado um impacto econômico positivo, mesmo que mínimo, para a Unidade Básica de Saúde (UBS) onde o serviço era prestado e para o sistema de saúde. Nesses termos, segundo Lyra Júnior (2005), cabe refletir o quanto a ATENFAR seria conveniente à realidade brasileira, pois a implementação de programas de ATENFAR nas UBS, atendendo grupos maiores de pacientes, poderia minimizar os gastos com internações ou complicações provocadas pela incidência de PRM, 
redirecionando os recursos públicos para a melhoria da estrutura e dos serviços do SUS, incluindo a expansão do acesso aos medicamentos.

$\mathrm{Na}$ Espanha, outro estudo que avaliou o impacto da ATENFAR foi o projeto TOMCOR (Therapeutic Outcomes Monitoring in Coronary Patients). Estudo multicêntrico desenhado pela Universidade da Flórida e desenvolvido na Espanha, que teve por objetivo avaliar os efeitos da ATENFAR sobre pacientes com doenças coronarianas. Os resultados deste estudo evidenciaram uma redução, porém não estatisticamente significativa, na taxa de novos infartos no grupo de intervenção e uma menor utilização de recursos sanitários devido aos infartos evitados. Além desses resultados, foi identificada no grupo intervenção uma melhora da qualidade de vida, um aumento do conhecimento sobre os fatores de risco da doença e sobre a medicação e, ainda, um aumento da satisfação com o serviço de saúde (TOLEDO et al., 2001).

Nos EUA, foi estimado que, quando farmacêuticos participam ativamente da revisão das prescrições e da orientação a pacientes idosos, quanto ao uso adequado da farmacoterapia, ocorre uma diminuição dos gastos do sistema de atenção à saúde com PRM, da ordem de US\$ 3,6 bilhões, por ano (ARAÚJO, 2001).

Estudo canadense, realizado pela Universidade de Laval, demonstrou que 69\% das intervenções do farmacêutico no tratamento farmacológico, representaram redução de custos para o serviço de saúde (GARIEPY, 1997).

Em 2004, profissionais do Instituto Nacional de Cardiologia de Laranjeiras, no Rio de Janeiro, divulgaram os resultados do serviço de ATENFAR prestado a pacientes portadores de hipertensão grave e de insuficiência cardíaca atendidos por aquele instituto. Os resultados mostraram que houve uma redução de $83 \%$ nos 
atendimentos de emergência e de cerca de 65\% nas internações após o início do serviço (SOLUÇÃO, 2005).

Segundo Pereira e Freitas (2007), a demonstração, frente à realidade brasileira, de que os benefícios proporcionados pela ATENFAR tenham maior valor monetário do que os custos de sua implantação e manutenção, é fator imprescindível para convencer os gestores dos serviços de saúde da necessidade e das vantagens da implantação de serviços de Atenção Farmacêutica.

É sabido que a solução para os complexos problemas encontrados no setor saúde será, na maioria das vezes, de natureza política. A avaliação econômica representa apenas uma técnica que, por si só, não é capaz de solucioná-los. Todavia, para um grande número de questões que desafiam os responsáveis pelas decisões, a utilização desse instrumento representa um auxílio valioso (BEVILÁQUA, 2001). Como relatado por Iglesias et al (2005), na América Latina, em Portugal, na Espanha e no Reino Unido, as decisões tomadas nos sistemas de saúde, em geral, não são fundamentadas em análises e avaliações econômicas, mas baseadas, primeiramente, na alocação de recursos segundo critérios políticos, registros históricos, áreas geográficas e grupos específicos de pacientes e de doenças.

É evidente que os resultados clínicos e humanísticos da atenção farmacêutica são muito benéficos para os usuários que usufruem desses serviços. Entretanto, estudos concretos, com metodologia bem definida, sobre os resultados econômicos do impacto da atividade de ATENFAR são poucos, principalmente no Brasil, pois os que existem, geralmente, não passam de estimativas, projeções ou suposições que abordam apenas o impacto da prestação da ATENFAR sobre o "custo da doença" (valor financeiro demandado por uma enfermidade), sem considerar os custos envolvidos com o serviço de atenção farmacêutica e sem compará-lo com outra 
tecnologia de saúde que, se aplicada em detrimento do mesmo, possa fornecer resultados aceitáveis para o tratamento sanitário em questão. Por essas razões, essa dissertação visa discutir aspectos relacionados à elaboração de metodologias para avaliações econômicas do impacto da atividade de ATENFAR, as quais devem ser realizadas para fundamentar decisões sobre a implantação dessa nova prática profissional em instituições e sistemas de saúde, como preconiza a Agenda Nacional de Prioridades de Pesquisa em Saúde do Departamento de Ciência e Tecnologia do Ministério da Saúde (MINISTÉRIO DA SAÚDE, 2004). 


\section{OBJETIVOS}

\subsection{OBJETIVO GERAL:}

Levantar informações acerca dos temas Economia da Saúde, Atenção Farmacêutica e Avaliação em Saúde e discutir criticamente a aplicabilidade e adequação dessas informações a avaliações econômicas do impacto da atividade de Atenção Farmacêutica na assistência à saúde.

\subsection{OBJETIVOS ESPECÍFICOS:}

- Identificar quais tipos de análises econômicas, empregados na área da saúde, são aplicáveis a avaliações econômicas do impacto da ATENFAR;

- Conhecer custos a serem apurados em avaliações econômicas do impacto da ATENFAR;

- Conhecer possíveis resultados gerados pela atividade de ATENFAR;

- Avaliar sobre quais perspectivas as análises econômicas do impacto da ATENFAR podem ser realizadas;

- Analisar quais modelos de estudos epidemiológicos são os mais indicados para serem utilizados em análises econômicas do impacto da ATENFAR. 


\section{MÉTODOS}

Neste trabalho foi realizada uma revisão bibliográfica narrativa acerca dos temas Economia da Saúde, Atenção Farmacêutica e Avaliação em Saúde, publicados a partir de 1986. Essa série histórica, escolhida para delimitar a seleção de publicações, aborda os últimos vinte anos e foi assim definida visto que os principais assuntos tratados neste estudo, Economia da Saúde, Avaliação em Saúde e Atenção Farmacêutica, são disciplinas relativamente novas. A referida escolha visa, também, obter informações atualizadas sobre tais assuntos.

\section{PASSO:}

Realizou-se busca por publicações afins com os objetivos do estudo, através de pesquisas diretas em bibliotecas convencionais (biblioteca do Departamento de Medicina Social da Faculdade de Medicina de Ribeirão Preto da Universidade de São Paulo e biblioteca Central do Campus de Ribeirão Preto da Universidade de São Paulo), em site de buscas na internet (www.google.com.br) e nos bancos eletrônicos de dados Pubmed/Medline (um serviço da Biblioteca Nacional de Medicina - National Library of Medicine - dos Estados Unidos da América), Dedalus (biblioteca virtual da Universidade de São Paulo), Lilacs (Literatura Latino-Americana e do Caribe de Informação em Ciências da Saúde), SciELO (Scientific Electronic Library Online) e biblioteca Cochrane, sendo os três últimos, serviços da Biblioteca Virtual em Saúde do Centro Latino-Americano e do Caribe de Informação em Ciências da Saúde (BIREME). 
Nas buscas realizadas nos bancos de dados e no site de buscas na internet, foram utilizados como palavras-chave os termos constantes no quadro 1 , nos idiomas Português, Espanhol e Inglês. Tais termos foram conjugados entre si, quando conveio, com o auxílio do operador booleano "and", visando restringir aos objetivos desta dissertação as publicações apresentadas como resultado das buscas.

\section{$2^{\circ}$ PASSO:}

As publicações encontradas foram classificadas como referências originais e de revisão e, então, foi feita a eliminação de duplicações.

As referências de revisão, cujos textos são um extrato sumário de todos os trabalhos utilizados em sua elaboração, além de terem sido utilizadas para compor este trabalho, também foram utilizadas para que se conhecesse, através das extensas listas bibliográficas que em geral as acompanham, um maior número de referências originais. 


\begin{tabular}{|c|c|c|}
\hline CÓDIGO & TEMA & PALAVRAS-CHAVE \\
\hline \multirow{7}{*}{ A } & \multirow{7}{*}{$\begin{array}{c}\text { ATENÇÃO } \\
\text { FARMACÊUTICA }\end{array}$} & atenção farmacêutica, atención farmacéutica, pharmaceutical care. \\
\hline & & $\begin{array}{l}\text { assistência farmacêutica, asistencia farmacéutica, pharmaceutical } \\
\text { assistance. }\end{array}$ \\
\hline & & $\begin{array}{l}\text { problemas relacionados com } \quad \text { medicamentos, } \\
\text { relacionados con medicamentos, medicine-related problems. }\end{array}$ \\
\hline & & $\begin{array}{l}\text { reações adversas aos medicamentos, reacciones adversas a los } \\
\text { medicamentos, adverse drugs reactions. }\end{array}$ \\
\hline & & $\begin{array}{l}\text { uso racional de medicamentos, uso racional de medicamentos, } \\
\text { rational drug use. }\end{array}$ \\
\hline & & $\begin{array}{l}\text { seguimento farmacoterapêutico, seguimiento farmacoterapéutico, } \\
\text { pharmacotherapy follow-up. }\end{array}$ \\
\hline & & farmácia clínica, farmacia clínica, clinical pharmacy. \\
\hline \multirow{10}{*}{$\mathrm{B}$} & \multirow{10}{*}{$\begin{array}{l}\text { ECONOMIA DA } \\
\text { SAÚDE }\end{array}$} & economia da saúde, economía de la salud, health economics. \\
\hline & & farmacoeconomia, farmacoeconomía, pharmacoeconomics. \\
\hline & & $\begin{array}{l}\text { custos de cuidados de saúde, costos de la atención en salud, } \\
\text { health care costs. }\end{array}$ \\
\hline & & $\begin{array}{l}\text { custos e análise de custo, costos y análisis de costo, costs and } \\
\text { cost analysis. }\end{array}$ \\
\hline & & sistemas de custos, sistemas de costos, costs systems. \\
\hline & & alocação de custos, asignación de costos, cost allocation. \\
\hline & & $\begin{array}{l}\text { análise custo-benefício, análisis costo-beneficio, cost-benefit } \\
\text { analysis. }\end{array}$ \\
\hline & & \begin{tabular}{|llll}
$\begin{array}{l}\text { análise custo-efetividade, análisis costo-efectividad, cost- } \\
\text { effectiveness analysis. }\end{array}$ & & \\
\end{tabular} \\
\hline & & $\begin{array}{l}\text { análise custo-minimização, análisis costo-minimización, cost- } \\
\text { minimization analysis. }\end{array}$ \\
\hline & & análise custo-utilidade, análisis costo-utilidad, cost-utility analysis. \\
\hline \multirow{10}{*}{ C } & \multirow{10}{*}{$\begin{array}{l}\text { AVALIAÇÃO EM } \\
\text { SAÚDE }\end{array}$} & avaliação em saúde, evaluación en salud, health evaluation. \\
\hline & & avaliação econômica, evaluación económica, economic evaluation. \\
\hline & & $\begin{array}{l}\text { avaliação de tecnologias, evaluación de tecnologías, technology } \\
\text { assessment. }\end{array}$ \\
\hline & & $\begin{array}{l}\text { avaliação da tecnologia biomédica, evaluación de la tecnología } \\
\text { biomédica, technology assessment biomedical. }\end{array}$ \\
\hline & & planejamento em saúde, planificación en salud, health planning. \\
\hline & & planificación estratégica, strategic \\
\hline & & $\begin{array}{l}\text { administração de serviços de saúde, administración de los } \\
\text { servicios de salud, health services administration. }\end{array}$ \\
\hline & & gestão em saúde, gestión en salud, health management. \\
\hline & & $\begin{array}{l}\text { saúde baseada em evidências, salud basada en evidencia, } \\
\text { evidence-based health. }\end{array}$ \\
\hline & & $\begin{array}{l}\text { medicina baseada em evidências, medicina basada en evidencia, } \\
\text { evidence-based medicine. }\end{array}$ \\
\hline
\end{tabular}

Quadro 1: Codificação de temas e relação de palavras-chave utilizadas na pesquisa. 


\section{$3^{\circ}$ PASSO:}

As publicações encontradas foram analisadas em um processo composto por três etapas consecutivas e eliminatórias, com o ideal de selecionar aquelas que pudessem conter informações relevantes para a presente pesquisa.

$\mathrm{Na}$ primeira etapa foram analisados os títulos de cada publicação para averiguar quais abordavam assuntos pertinentes aos objetivos desta dissertação.

$\mathrm{Na}$ segunda etapa foi realizada a leitura dos resumos das publicações selecionadas na primeira etapa, a fim de averiguar a adequação desses estudos aos objetivos deste trabalho.

$\mathrm{Na}$ terceira etapa foi realizada a leitura integral das publicações selecionadas na segunda etapa e também daquelas selecionadas na primeira e que não continham resumo em sua estrutura que, por conseguinte, não sofreram a averiguação proposta na segunda etapa. A leitura integral das referidas publicações visou analisar a coerência entre proposta, metodologia e resultados das mesmas.

\section{$4^{\circ}$ PASSO:}

As publicações selecionadas foram organizadas de acordo com o tema principal, recebendo cada qual um código que o relacionava com um dos três grandes temas de interesse dessa pesquisa, explicitados no quadro 1.

O intuito da codificação foi organizar as publicações por assunto para facilitar a busca por informações temáticas específicas. 


\section{PASSO:}

Realizou-se, junto às publicações selecionadas, a busca por informações referentes aos objetivos específicos desse trabalho e discutiu-se criticamente tais informações, com o intuito de analisar a adequação e a aplicabilidade das mesmas. 


\section{RESULTADOS E DISCUSSÃO}

A revisão de literatura oferece meios para definir e resolver não somente problemas já conhecidos, como também explorar novas áreas onde os problemas não se "cristalizaram" suficientemente, conforme afirmam Lakatos e Marconi (1997).

Gil (1996) coloca que, em uma revisão bibliográfica, a utilização de bancos de dados permite aos pesquisadores obter maior cobertura do assunto pesquisado que através de uma pesquisa direta, porém essa prática possui alguns limites, pois usando somente as palavras-chave diretamente relacionadas ao tema de estudo, não se atinge toda a produção científica relativa àquele tema, sendo necessário utilizar termos "secundários" e, mesmo assim, deixa-se de detectar algumas publicações de grande relevância que não constam em bancos de dados.

Pelos motivos expostos por GIL (1996), durante o desenvolvimento de uma revisão bibliográfica, há necessidade de realizar buscas por publicações não somente em bases de dados, mas também através de outros meios como a pesquisa direta em bibliotecas convencionais e a internet, tal como foi realizado o presente estudo.

Nesse estudo não foi possível conhecer toda a produção científica relativa aos temas estudados, tampouco se ousou querer esgotar aqui a discussão de tais temas. Entretanto, muitos dos mais citados trabalhos e autores foram consultados e utilizados para compor essa dissertação.

As informações obtidas nas referências consultadas permitiram que os objetivos propostos fossem alcançados após a análise dos resultados da pesquisa bibliográfica, os quais são apresentados neste tópico do trabalho. 


\subsection{ATENÇÃO FARMACÊUTICA}

O conceito de Atenção Farmacêutica começou a ser construído, inconscientemente, em 1975 por Mikeal et al., através da publicação de um trabalho que visava nortear e estender a atuação do profissional farmacêutico para as ações de atenção primária em saúde, tendo o medicamento como insumo estratégico e o paciente como foco principal. Nesse trabalho os autores afirmaram que o farmacêutico deveria prestar a "atenção que dado paciente requer e recebe com garantias de um uso seguro e racional dos medicamentos" (MIKEAL et. al, 1975 apud PEREIRA; FREITAS, 2007) ${ }^{1}$.

Alguns anos depois, Brodie, Parish e Poston (1980) complementaram a proposta de Mikeal et al., afirmando que o farmacêutico deveria atuar na "definição das necessidades farmacoterapêuticas de um dado paciente e na provisão não apenas dos medicamentos requeridos, mas também dos serviços necessários (antes, durante e depois do uso de medicamentos) para assegurar uma terapia perfeitamente segura e efetiva" (BRODIE; PARISH; POSTON, 1980 apud LYRA JÚNIOR, 2005) ${ }^{2}$.

Em 1987, Hepler descreveu que a atuação do farmacêutico nas ações de atenção primária em saúde deve se dar através da "relação conveniente entre o farmacêutico e o paciente, na qual o farmacêutico realiza as funções de controle sobre o uso dos medicamentos (com apropriado conhecimento e habilidade), guiado por sua consciência e compromisso com os interesses do paciente".

\footnotetext{
${ }^{1}$ MIKEAL, R. L. et al. Quality of Pharmaceutical Care in Hospitals. American Journal of Hospital Pharmacy. n. 32, p. 567-574. 1975.

${ }^{2}$ BRODIE, D. C.; PARISH, P. A.; POSTON, J. W.. Societal Needs for Drugs and Drug Related Services. American Journal of Pharmaceutical Education. v. 44, p. 276-278. 1980.
} 
Três anos mais tarde Hepler, em parceria com Strand, definiram o que seria a prática denominada ATENFAR (Pharmaceutical Care), como "o fornecimento responsável de medicamentos com o objetivo de atingir o resultado desejado, que levará a uma melhoria na qualidade de vida do paciente" (HEPLER; STRAND, 1990).

Com o trabalho desses professores, e, após o estabelecimento dessa definição, a ATENFAR começa a surgir para todo o mundo, sendo estudada e implementada em diversos países, principalmente no ocidente e na Austrália.

No ano de 1993, a Associação Americana de Farmacêuticos de Hospital e Sistemas de Saúde (ASHP), baseada nos trabalhos de Hepler e Strand (1990), estabeleceu que ATENFAR é "a direta e responsável provisão de cuidados relacionados com a medicação, com o propósito de alcançar resultados que sirvam para melhorar a qualidade de vida do paciente" (ASHP, 1993).

Neste mesmo ano, a Organização Mundial de Saúde (OMS), com o propósito de estabelecer uma diretriz para as discussões sobre ATENFAR, define que atenção farmacêutica é "o conjunto de atitudes, comportamentos, compromissos, inquietações, valores éticos, funções, conhecimentos, responsabilidades e destrezas do farmacêutico na prestação da farmacoterapia, com o objetivo de alcançar resultados terapêuticos definitivos na saúde e na qualidade de vida da população, sendo o paciente o principal beneficiário das ações farmacêuticas" (OMS, 1988).

Em 1997, Strand lança um novo conceito de ATENFAR, por achar que o conceito definido em 1990, na companhia de Hepler, estava incompleto. No novo conceito, Strand diz que a ATENFAR é "a prática na qual o profissional assume a responsabilidade pela definição das necessidades farmacoterápicas do paciente e o compromisso de resolvê-las" (STRAND, 1997). 
Após criarem seus grupos de estudos, cada qual em diferentes universidades americanas, Hepler e Strand, desenvolveram métodos distintos de acompanhamento à farmacoterapia do paciente, resultando em dois modelos diferentes de ATENFAR.

Hepler et al. desenvolveram o modelo denominado Therapeutic Outcomes Monitoring (TOM) ou, em português, Monitoração dos Resultados Terapêuticos, para prestação de ATENFAR, com foco no cuidado de doenças crônicas, usando a asma como protótipo (GRAINGER-ROUSSEAU et al., 1997; GOURLEY et al., 1998; CIPOLLE; STRAND; MORLEY, 2002; HERBORG et al., 2001a,b; NÄRHI et al., 2000).

Strand, liderando um grupo de pesquisadores em Minnesota, nos Estados Unidos, criou o método chamado Pharmacist's Workup of Drug Therapy (PWDT) que pode ser traduzido para o português como Avaliação Sistemática da Farmacoterapia pelo Farmacêutico. Este modelo, ao contrário do modelo TOM, contempla todos os tipos de situações e doenças, sendo focado na prevenção e resolução de PRM e não em uma doença crônica de base (LYRA JÚNIOR, 2005).

Em 1998, um grupo de farmacêuticos de Granada, na Espanha, se reuniu com intuito de debater a ATENFAR. Neste encontro, denominado Primeiro Consenso de Granada, a ATENFAR foi definida como "a participação ativa do farmacêutico em atividades de promoção à saúde e prevenção de doenças e na assistência direta ao paciente na dispensação e seguimento do tratamento farmacoterápico, cooperando com o médico e outros profissionais de saúde, a fim de conseguir resultados que melhorem a qualidade de vida dos pacientes" (PANEL DE CONSENSO, 1999; CIPOLE; STRAND; MORLEY, 2002). 
Este grupo de farmacêuticos elaborou, ainda, uma metodologia para a implantação e seguimento do tratamento farmacológico de pacientes, destinada a formar profissionais farmacêuticos voltados para a ATENFAR. Tal metodologia foi denominada método Dáder de acompanhamento farmacoterapêutico, o qual, assim como o PWDT elaborado pelo grupo de Minnesota, pode ser aplicado sistematicamente para todos os tipos de situações e doenças, e, além disso, baseiase nos problemas de saúde apresentados pelo paciente para identificar e resolver PRM (FAUS, 2000; LYRA JÚNIOR, 2005).

Pelo fato de poderem ser aplicados sistematicamente para todos os tipos de situações e doenças, o método espanhol Dáder e o método americano PWDT são os modelos de ATENFAR mais utilizados por pesquisadores e farmacêuticos em todo o mundo, entretanto, existem diferenças entre eles, principalmente na classificação dos problemas farmacoterapêuticos ou PRM.

No Brasil não há um consenso oficial sobre a definição de atenção farmacêutica, existe apenas uma proposta de consenso, na qual se conceitua a ATENFAR como "um modelo de prática farmacêutica, desenvolvida no contexto da assistência farmacêutica. Compreende atitudes, valores éticos, comportamentos, habilidades, compromissos e co-responsabilidades na prevenção de doenças, promoção e recuperação da saúde, de forma integrada à equipe de saúde. É a interação direta do farmacêutico com o usuário, visando uma farmacoterapia racional e obtenção de resultados definidos e mensuráveis, voltados para a melhoria da qualidade de vida do paciente. Esta interação também deve envolver as concepções dos seus sujeitos, respeitadas as suas especificidades bio-psicosociais, sob a ótica da integralidade das ações de saúde" (OPAS, 2002a). 
A ATENFAR é uma atividade originada da chamada Farmácia Clínica, prática farmacêutica definida pela ASHP como "a ciência da saúde cuja responsabilidade é assegurar, mediante a aplicação de conhecimentos e funções relacionados ao cuidado dos pacientes, que o uso dos medicamentos seja seguro e apropriado, e que necessita, portanto, de educação especializada e interpretação de dados, da motivação por parte do paciente e de interações multiprofissionais" (ARANCIBIA et al., 1993; MENEZES, 2000; STORPIRTIS; RIBEIRO; MARCOLONGO, 2001).

Segundo Holand e Nimmo (1999), farmácia clínica é "uma prática que aprimora a habilidade do médico para tomar decisões sobre os medicamentos. Ao médico cabe a responsabilidade pelos resultados da farmacoterapia e, ao farmacêutico, proporcionar serviços de suporte adequados e conhecimentos especializados sobre o uso de medicamentos à equipe de saúde".

Embora sejam por vezes confundidas, a ATENFAR e a Farmácia Clínica não são a mesma atividade. Como descrito anteriormente, a primeira é oriunda da segunda. Nela o farmacêutico utiliza métodos específicos para prestar assistência ao paciente, tendo esse como foco principal de suas ações, enquanto a Farmácia Clínica enfoca, principalmente, o cuidado sanitário em si.

A ATENFAR é tida como uma "ferramenta" da Farmácia Clínica que utiliza, além dos conhecimentos clínicos, conhecimentos humanísticos (educacionais, psicológicos, sociológicos), para prestar o cuidado farmacêutico aos pacientes e, muitas vezes, aos familiares e cuidadores desses pacientes. Dessa forma, a atividade de ATENFAR não se resume à simples análise e acompanhamento da farmacoterapia prescrita e dos desfechos clínicos da utilização dos medicamentos. Ela exige que o farmacêutico seja sensível e capacitado, suficientemente, para lidar 
com questões físico-biológicas, psíquicas e sociais, relacionadas aos pacientes e à seus entes, abrangendo, de forma ampla, a condição de saúde desses indivíduos.

Freqüentemente, o termo Atenção Farmacêutica também é confundido ou até mesmo utilizado como sinônimo do termo Assistência Farmacêutica. Dupim (1999) colaborou para esclarecer dúvidas entre esses dois importantes conceitos. Segundo o autor, a Assistência Farmacêutica é "um processo que visa à proteção ou à recuperação da saúde, em nível individual ou coletivo, englobando procedimentos relativos à produção, seleção, preparação, aquisição, armazenamento, distribuição, prescrição e dispensação de medicamentos, dela participando profissionais de diferentes áreas além da farmácia". Tal atividade não deve ser confundida com a Atenção Farmacêutica, prática que diz respeito à relação do farmacêutico com o paciente, do mesmo modo que a atenção médica não se confunde com assistência médica, mais ampla e abrangente. Desse modo, verifica-se que a ATENFAR está compreendida na Assistência Farmacêutica.

Corroborando com a distinção realizada por Dupim (1999), a proposta de Consenso Brasileiro de Atenção Farmacêutica (2002) também estabelece que a Assistência Farmacêutica e a ATENFAR são conceitos distintos. O último está inserido nas atividades específicas do farmacêutico no âmbito da atenção à saúde, enquanto o primeiro envolve um conjunto mais amplo de ações, com características multiprofissionais (OPAS, 2002a).

A ATENFAR é uma atividade que pode ser desenvolvida com pacientes hospitalizados, com pacientes atendidos em farmácias comunitárias, em farmácias de unidades básicas de saúde ou com pacientes tratados em seu domicílio, e tem como componentes gerais a educação em saúde (incluindo promoção do uso racional de medicamentos), a orientação farmacêutica, a dispensação, a entrevista 
farmacêutica, o seguimento/acompanhamento farmacoterapêutico, o registro sistemático das atividades e a mensuração e avaliação dos resultados, buscando sempre a melhoria das condições clínicas e humanísticas dos pacientes, decorrentes da redução da morbimortalidade ocasionada por medicamentos, através de ações que estimulem a adesão dos pacientes aos tratamentos e que previnam, detectem e tratem eventuais PRM que possam surgir no decorrer dos tratamentos (GENUA; MIRÓ, 1996; OPAS/OMS, 1997; CIPOLLE; STRAND; MORLEY, 2002; OPAS, 2002a; BISSON, 2003).

Os PRM ou problemas farmacoterapêuticos, como o grupo de pesquisadores de Minnesota assim os denominou, foram definidos por este mesmo grupo em 1998 como "qualquer evento indesejável experimentado pelo paciente que envolva ou se suspeite que envolva a farmacoterapia e que interfira real ou potencialmente com um resultado esperado no tratamento sanitário deste paciente". O grupo complementou o conceito dizendo que o evento indesejável que interfere ou pode interferir no resultado esperado não se restringe a enfermidades e sintomas, podendo ser, também, qualquer problema relacionado com os aspectos psicológicos, fisiológicos, socioculturais ou econômicos (CIPOLLE; STRAND; MORLEY, 2002). Esses autores identificaram sete problemas farmacoterapêuticos que são classificados conforme o Quadro 2 (STRAND et al., 2004):

\begin{tabular}{|l|l|}
\hline \multirow{2}{*}{ Classificação } & Problema Farmacoterapêutico (PF) \\
\hline \multirow{2}{*}{ Necessidade } & PF 1: Necessita de tratamento farmacológico adicional \\
\cline { 2 - 2 } & PF 2: Tratamento farmacológico desnecessário \\
\hline \multirow{2}{*}{ Efetividade } & PF 3: Medicamento inadequado \\
\cline { 2 - 2 } & PF 4: Dose do medicamento inferior à necessitada \\
\hline \multirow{2}{*}{ Segurança } & PF 5: Dose do medicamento superior à necessitada \\
\cline { 2 - 2 } & PF 6: Reação Adversa aos Medicamentos \\
\hline Adesão & PF 7: Adesão inapropriada ao tratamento farmacológico \\
\hline
\end{tabular}

Quadro 2: Classificação de problemas farmacoterapêuticos, segundo o grupo de Minnesota. 
Durante o Primeiro Consenso de Granada, realizado em 1998 na cidade espanhola de mesmo nome, o grupo de pesquisadores que lá se reuniu propôs um conceito de PRM que se fundamentou nos conceitos publicados pelo Grupo de Minnesota, o qual definiu PRM como "um problema de saúde, vinculado com a farmacoterapia e que interfere ou pode interferir nos resultados de saúde esperados de um paciente, sendo que problema de saúde é tudo que requer ou pode requerer uma ação por parte dos agentes de saúde, incluindo o próprio paciente". Nesta ocasião, os PRM foram classificados com base nas chamadas três necessidades fundamentais da farmacoterapia, que podem ser vistas no Quadro 3 (PANEL DE CONSENSO, 1999; LLIMÓS; ROMERO; FAUS, 1999; HERRERA-CARRANZA, 2002):

\begin{tabular}{|l|l|}
\hline Classificação & Problema Relacionado ao Medicamento (PRM) \\
\hline Necessidade & PRM 1: o paciente não usa os medicamentos que necessita \\
\cline { 2 - 2 } & PRM 2: o paciente usa medicamentos que não necessita \\
\hline \multirow{3}{*}{ Efetividade } & $\begin{array}{l}\text { PRM 3: o paciente usa um medicamento prescrito que foi } \\
\text { mal selecionado }\end{array}$ \\
\cline { 2 - 2 } & $\begin{array}{l}\text { PRM 4: o paciente faz uso de uma posologia inferior à } \\
\text { necessária }\end{array}$ \\
\hline \multirow{2}{*}{ Segurança } & $\begin{array}{l}\text { PRM 5: o paciente faz uso de uma posologia superior à } \\
\text { necessária }\end{array}$ \\
\hline & $\begin{array}{l}\text { PRM 6: o paciente usa um medicamento que provoca nele } \\
\text { uma reação adversa }\end{array}$ \\
\hline
\end{tabular}

Quadro 3: Classificação de problemas relacionados aos medicamentos, baseada nas três necessidades fundamentais da farmacoterapia, segundo o Primeiro Consenso de Granada.

Em 2002, no Segundo Consenso de Granada, o conceito de PRM elaborado pelo grupo espanhol foi redefinido, passando a ser descrito como "problema de saúde, entendido como resultados clínicos negativos derivados da farmacoterapia que são produzidos por diversas causas e tem como conseqüência o não alcance do objetivo terapêutico desejado ou o aparecimento de efeitos indesejáveis" (PANEL DE CONSENSO, 2002). 
A principal diferença entre a classificação dos problemas farmacoterapêuticos, definidos pelo grupo de Minnesota, e a classificação dos PRM, definido pelo grupo de Granada, baseia-se na adesão ao tratamento, pois, para o grupo de Minnesota, a não adesão é considerada um problema farmacoterapêutico, enquanto que, para o grupo de Granada, a não adesão ao tratamento é considerada uma causa de PRM e não um PRM propriamente dito.

De acordo com a Proposta de Consenso Brasileiro de ATENFAR, o termo PRM refere-se a "um problema de saúde, relacionado ou suspeito de estar relacionado à farmacoterapia, que interfere ou pode interferir nos resultados terapêuticos e na qualidade de vida do usuário" (OPAS, 2002a).

Os PRM são freqüentes em todas as faixas etárias e comuns em todo o mundo. Nos EUA, só em 1997, foram gastos US\$ 14 bilhões em internações hospitalares para tratar pacientes hipertensos, que não aderiram à farmacoterapia (BENSON, VANCE-BRYAN, RADDATZ, 2000). Segundo Pepe e Castro (2000), riscos associados à terapêutica podem ser minimizados pelo investimento na melhoria da qualidade da prescrição e da dispensação de medicamentos.

A prevenção de PRM deve ocorrer através do fomento ao uso racional de medicamentos, que "é o processo que compreende a prescrição apropriada, a disponibilidade oportuna e a preços acessíveis, a dispensação em condições adequadas, e o consumo nas doses indicadas, nos intervalos definidos e no período de tempo indicado; de medicamentos eficazes, seguros e de qualidade" (MINISTÉRIO DA SAÚDE, 2001).

Quando estimulado no nível da atenção básica à saúde, o URM pode evitar uma hospitalização custosa, tanto em recursos monetários, quanto em sofrimento para o paciente (OLSSON et al., 1994; SULLIVAN, 1996; HODGSON; CAI, 2001). 
O uso racional de medicamentos inclui (SOBRAVIME; AIS, 2001):

- Escolha adequada de terapêutica;

- Indicação apropriada, isto é, prescrição baseada em evidências clínicas;

- Medicamento apropriado, considerando-se eficácia, segurança, conveniência para o paciente e custo;

- Posologia, administração e duração do tratamento adequado;

- Paciente apropriado, isto é, inexistência de contra-indicação e mínima probabilidade de reações adversas;

- Dispensação correta, incluindo informação apropriada sobre os medicamentos prescritos;

- Adesão ao tratamento por parte do paciente.

Segundo Le Grand; Hogerzeil; Haaijer-Ruskamp (1999) e Vieira (2007), o uso irracional de medicamentos é um importante problema de saúde pública em todo o mundo e que gera grandes conseqüências econômicas. Todavia, quando utilizados apropriadamente, os medicamentos são, na maioria das vezes, o recurso terapêutico mais eficaz no processo de restituição da saúde do paciente (MC ISAAC et al., 1994).

De acordo com Bisson (2003) a ATENFAR é uma prática que tem o objetivo principal de, através do estímulo ao URM, melhorar a condição de saúde e a qualidade de vida dos pacientes que fazem uso de terapia medicamentosa, mediante o alcance de resultados definidos, que podem ser traduzidos de maneira genérica como:

- Cura da doença do paciente;

- Eliminação ou redução de uma sintomatologia da doença;

- Estagnação do progresso ou retrocesso da doença; 
- Prevenção de nova doença, de uma sintomatologia ou de iatrogenias.

Esses resultados genéricos foram expostos de forma específica através de diversos estudos realizados para avaliar a atividade de ATENFAR. Os resultados específicos, de acordo com Lyra Júnior (2005), podem ser de três tipos: resultados clínicos, resultados humanísticos e resultados econômicos, os quais são utilizados nas análises econômicas tipo custo-minimização e tipo custo-efetividade, na análise tipo custo-utilidade e na análise tipo custo-benefício, respectivamente.

Os resultados clínicos estão associados ao estado de saúde do paciente e são expressos em número de PRM evitados, porcentagens de curas alcançadas, aumento de sobrevida, número de internações evitadas, melhoria em parâmetros vitais como a pressão arterial e a glicemia (JABER et al., 1996; BLUML; MC KENNEY; CZIRAKY, 2000; GARÇÃO; CABRITA, 2002; ROMANO-LIEBER et al., 2002; TIMBS, 2002; ODEGARD et al., 2005).

Os humanísticos estão centrados na qualidade de vida que é um conceito muito amplo e envolve não apenas a saúde, mas também a percepção global do paciente de um determinado número de dimensões-chaves, com ênfase em (TORRANCE, 1986; DANTAS; SAWADA; MALERBO, 2003):

- Características físicas, biológicas, anatômicas e hereditárias;

- Estado funcional e a capacidade de desempenhar as atividades do cotidiano;

- Estado mental, incluindo a auto-percepção da saúde e do estado de ânimo;

- Potencial de vida individual, que inclui a longevidade e o prognóstico dos eventuais estados mórbidos;

- Fatores ambientais, que incluem a situação socioeconômica, a educação, os hábitos de higiene, a alimentação e o meio ambiente, entre outros. 
Em geral, os resultados humanísticos são expressos através de coeficientes de qualidade de vida ou do fator denominado AVAQ (anos de vida ajustados pela qualidade) (DRUMMOND et al., 1997; MOTA, 2003; MOTA; FERNANDES; COELHO, 2003).

O terceiro tipo de resultados diz respeito aos resultados econômicos, que "traduzem", em termos monetários, os resultados clínicos e humanísticos. Os resultados econômicos, geralmente, expressam o montante de recursos economizados através da redução da hospitalização; do número de consultas médicas; da diminuição do tempo médio de internação e das consultas de emergência; da diminuição do absenteísmo no trabalho; do maior rendimento laboral em virtude da melhoria na qualidade de vida; da extinção da necessidade de um cuidador; da diminuição do número, diversidade e/ou complexidade dos medicamentos utilizados (SCHNEIDER; GIFT; LEE,1995; DRUMMOND et al., 1997; LYRA JÚNIOR, 2005).

Apesar da grande variedade e das várias classificações adotadas, todos os resultados da ATENFAR implicam em três funções principais, inerentes ao profissional farmacêutico (BISSON, 2003):

1. Identificação de problemas potenciais e reais relacionados aos medicamentos;

2. Resolução de problemas atuais com medicamentos;

3. Prevenção de problemas potenciais relacionados aos medicamentos.

Bisson (2003), afirma também que, para se alcançar resultados efetivos com a prática da ATENFAR, é preciso prover a estrutura necessária ao desenvolvimento dessa prática, iniciando com a realização de um planejamento bem feito, contemplando as facilidades e os obstáculos que poderão ser encontrados, assim 
como alternativas para transpor esses obstáculos, além da mensuração de todos os recursos que serão demandados como:

- Infra-estrutura física e humana necessárias para o desenvolvimento das atividades [salas, consultório privativo, móveis (mesa redonda, cadeiras confortáveis), computadores com softwares e hardwares necessários ao bom desenvolvimento do serviço, funcionários qualificados e em número suficiente (farmacêuticos, auxiliares, escriturários, recepcionista), educação continuada dos funcionários] (ELLIS et al., 2000; BERGER, 2002; ROMANO-LIEBER et al.; 2002; LA PLANTE; HARRINGTON; KANG, 2002; SILVA, 2003b);

- Fontes de informação primárias, secundárias e terciárias que devem estar disponíveis (internet, livros, guias, revistas, bases de dados) (LLIMÓS, 1999; LYRA JÚNIOR, 2005);

- Material que será consumido para elaboração de material educativo e nos procedimentos de secretariado do serviço (papel, impressos, impressora, material de escritório);

- Transporte, caso necessário, da equipe que prestará o serviço de ATENFAR (LA PLANTE; HARRINGTON; KANG, 2002).

Todos esses recursos demandados implicam em custos do serviço de ATENFAR e serão peculiares, assim como os resultados, ao local onde o serviço será desenvolvido (hospitais, farmácias comunitárias, unidades básicas de saúde, domicílio), ao perfil dos pacientes que serão atendidos (sócio-econômico, escolaridade, idade, sexo, religião, gestantes) e ao perfil epidemiológico de patologias primárias (doenças crônicas) e secundárias (doenças agudas) na região (diabetes, hipertensão arterial, asma, câncer, osteoporose, doenças reumáticas, doenças infecciosas). 
Devido ao fato da prestação de ATENFAR ser precedida da proposição de uma terapia medicamentosa ao paciente e ao fato desta atividade ser desenvolvida em um serviço de saúde ou no domicílio do paciente, ao se levantar o custo total de tratamentos sanitários que disponham de um serviço de ATENFAR, os custos com toda a equipe sanitária (médicos, enfermeiros, pessoal de apoio), de manutenção dos serviços de saúde (água, luz, aluguel, telefone, manutenção, funcionários) e de transporte do paciente ou da equipe de ATENFAR, também devem ser computados, além dos custos relacionados diretamente com o desenvolvimento desse serviço e dos custos provenientes das condições clínicas do paciente.

Kozma, Reeder e Schulz (1993), ao examinarem a prática farmacêutica, no que tange às avaliações da estrutura e dos resultados de serviços farmacêuticos especializados, como a ATENFAR, acharam inconsistentes os resultados das avaliações desses serviços. Com o objetivo de oferecer aos farmacêuticos uma alternativa para conhecer melhor e avaliar a qualidade dos resultados de suas intervenções, eles criaram o chamado ECHO (Economic, Clinical and Humanistic Outcomes) model. Este modelo de avaliação baseia-se, fundamentalmente, na análise simultânea dos resultados clínicos, humanísticos e econômicos das intervenções farmacêuticas. Portanto, uma pesquisa que busque avaliar, por completo, os impactos de um serviço de ATENFAR, deve ter um desenho adequado, baseado nos preceitos do ECHO model (PANEL DE CONSENSO, 2002).

Como "profissional do medicamento", o farmacêutico deve ser o principal profissional envolvido no combate ao seu uso irracional, realizando a atenção farmacêutica e avaliando os impactos dessa atenção nas ações de saúde pública. Além disso, o farmacêutico atua como o último elo entre a prescrição e a administração dos medicamentos, e, por essa razão, a interação deste profissional 
com os demais profissionais de saúde pode contribuir, significativamente, para a melhoria da farmacoterapia (O'BRIEN, 2003).

No Brasil, além da garantia do acesso da população aos serviços de saúde e a medicamentos de qualidade, é necessária a implantação de práticas assistenciais como a ATENFAR, que promovam o uso racional de medicamentos, propiciando resultados que influenciem diretamente os indicadores sanitários, visto que o país encontra-se entre os dez maiores mercados consumidores de medicamentos do mundo (OPAS, 2002b). Entretanto, a prática clínica do farmacêutico ainda é incipiente em nosso país. Das poucas iniciativas existentes, a maioria é oriunda de universidades e de alguns hospitais, sendo ainda menores as iniciativas provenientes do Sistema Único de Saúde e de farmácias, drogarias e outras instituições privadas.

Uma experiência bem sucedida de implantação de serviço de ATENFAR na rede pública de saúde, ocorreu na cidade de Ribeirão Preto no interior do estado de São Paulo. Hoje o serviço de ATENFAR implantado na rede pública do município serve de modelo não só para o estado de São Paulo, mas para todo o país. De acordo com Mestriner (2003), durante o período de implementação do serviço de ATENFAR em algumas UBS do município, a equipe de farmacêuticos se posicionou de forma resistente às mudanças, devido principalmente às dificuldades referentes aos recursos humanos, porém, posteriormente, houve unanimidade quanto à satisfação e ao reconhecimento profissional por parte da equipe de saúde e da clientela. No decorrer da implantação desse novo modelo, ficou claro a preocupação dos farmacêuticos em participarem de uma nova proposta, que incorpora a atividade clínica como inerente à sua formação, demonstrando que esse aprendizado ainda é incipiente durante a formação acadêmica. 
A formação deficitária de farmacêuticos qualificados para exercer atividades clínicas, dentre elas a ATENFAR, é um dos principais empecilhos para a propagação dessa prática dentro do sistema de saúde brasileiro. Buscando suprir essa lacuna, as universidades brasileiras vêm discutindo a inserção obrigatória da disciplina nos cursos oferecidos no país, através da atualização e modernização das diretrizes curriculares para o curso de graduação em farmácia. Além disso, várias instituições passaram a oferecer, nos últimos anos, cursos de pós-graduação na área, que até pouco tempo não eram oferecidos no Brasil.

Hepler (2000), refletindo sobre o desenvolvimento da ATENFAR, ressalta que essa atividade é um processo, sendo possível aprender fazendo. Essa citação do conceituado pesquisador americano, serve como incentivo para que novos serviços de farmácia clínica e de ATENFAR sejam implementados em nosso país, propiciando o aprimoramento de mão-de-obra e o avanço nos conhecimentos nacionais sobre tais atividades.

Segundo os autores Pereira e Freitas (2007), para que haja a implementação efetiva da ATENFAR no setor público, os gestores devem ser conscientizados que esta atividade reduz custos para o sistema sanitário e melhora a qualidade de vida dos pacientes. No setor privado, a implementação da ATENFAR será possível quando os empresários se derem conta que a ATENFAR pode representar o diferencial de seu negócio, contribuindo para a fidelização de seus clientes através da prestação de serviço especializado. 


\subsection{AVALIAÇÃO EM SAÚDE}

A avaliação representa uma atividade bastante antiga, presente desde os primórdios na história da humanidade (CONTANDRIOPOULOS; CHAMPAGNE; PINEAULT, 1997).

Avaliar consiste, fundamentalmente, em fazer um julgamento do mérito, valor ou significância a respeito de uma intervenção ou sobre qualquer um de seus componentes, com o objetivo de ajudar na tomada de decisões. Esta definição formulada por Contrandriopoulos, Champagne e Pineault (1997) é apenas uma de diversas definições existentes para o termo avaliação.

Para Cohen e Franco (1998), o conceito mais adequado de avaliação é aquele que considera a eficiência, entendida como a minimização dos custos dos insumos ou maximização dos produtos, e a eficácia, que é o grau em que são alcançados os objetivos do projeto. Em síntese, a avaliação é a "atividade que tem como objetivo determinar a opção capaz de maximizar a eficácia dos programas na obtenção de seus fins e a eficiência na alocação de recursos para a consecução dos mesmos".

Em 1997, Bowling definiu avaliação como "o uso do método científico e a coleta de dados sistemática e rigorosa para aferir a efetividade de serviços e programas ao atingir seus objetivos".

De acordo com Silva e Formigli (1994), verifica-se, freqüentemente, uma superposição entre as definições de eficácia, eficiência e efetividade. Diante disso, é conveniente fazer a diferenciação entre tais termos.

Eficiência é "a capacidade de atingir um determinado resultado da maneira mais simples, utilizando a menor quantidade de insumos possível ou ainda a 
capacidade de, utilizando uma determinada quantidade de insumos, obter o melhor resultado possível" (DONABEDIAN, 1988; VIACAVA et al., 2004).

A eficácia é "a capacidade de atingir o efeito ótimo produzido em determinadas condições experimentais". (CAVALLO et al., 1988; DONABEDIAN, 1988).

Já a efetividade é "a capacidade de se atingir o efeito ótimo produzido em condições reais, em um sistema operacional" (CAVALLO et al., 1988; DONABEDIAN, 1988). É um atributo composto pela eficiência e pela eficácia.

Segundo Tanaka e Melo (2004), para quem está trabalhando em programas e/ou serviços de saúde, a avaliação é um processo técnico-administrativo destinado à tomada de decisão. Tal processo envolve momentos de medir, comparar e emitir juízo de valor e visa tornar o ato decisório o mais racional e efetivo possível.

No campo da Saúde Pública, a avaliação de serviços é área de extrema relevância, já que viabiliza escolhas de planejamento e possibilita um controle técnico e social dos serviços e programas prestados à sociedade (DESLANDES, 1997). Na atual conjuntura econômica mundial, o alto custo da atenção à saúde, seja pelo aumento da sua cobertura ou da sua complexidade, tem exigido dos gestores decisões que beneficiem o maior número possível de usuários e que consigam resultados mais eqüitativos com os mesmos recursos disponíveis (TANAKA; MELO, 2000).

Conforme descrito por Castro (2002), a avaliação não pode ser "um fim em si mesma", ela deve servir de suporte para o processo de tomada de decisão. O uso das técnicas avaliativas que identificam os problemas, as possibilidades de solução e que propõem o uso mais adequado dos recursos, possibilita aos gestores de saúde racionalizar tal processo. 
Para realizar uma avaliação, é condição necessária analisar as informações disponíveis para melhor conhecer a situação que será avaliada. Para isso, é preciso distinguir a análise de informações para a realização de uma avaliação, de um mero diagnóstico. A análise distingui-se do diagnóstico por exigir, além da descrição da situação que se quer conhecer, uma busca pelas possíveis explicações para a situação analisada (TANAKA; MELO, 2004).

O conceito primordial de avaliação é oriundo das ciências econômicas e é utilizado com variações por outras ciências, principalmente na área social (CASTRO, 2002). No setor sanitário, a avaliação foi inserida pelos profissionais ligados à saúde coletiva, sendo utilizada como instrumento de estudo sobre o impacto de determinada intervenção sobre a saúde da população, sua efetividade e custos, estudos sobre a estrutura e os processos relativos aos serviços de saúde, até a satisfação dos usuários com o serviço (VIEIRA, 2005).

Segundo Sala (1997) existem diversas propostas e trabalhos envolvendo avaliação em saúde, que podem ser resumidas em cinco linhas principais:

1. Relação entre demanda e serviços oferecidos, procurando avaliar a adequação entre a necessidade de saúde em função do tipo e quantidade de serviços oferecidos;

2. Análise da estrutura em termos de recursos e atividades desenvolvidas;

3. Avaliação do atendimento, analisando a atenção recebida pelo paciente, a eficácia do mesmo ou a adequação deste a um padrão previamente estabelecido;

4. Avaliação da relação entre o custo e o benefício do atendimento produzido. Esta avaliação é de fundamental importância para a realocação de gastos, com bom uso dos recursos financeiros disponíveis; 
5. Avaliação do efeito que o atendimento produz na população sobre a qual atua, medindo o impacto ou os resultados de determinadas intervenções.

Tanaka e Melo (2004) ressaltam que, ao realizar uma avaliação em programas ou serviços de saúde, deve-se considerar que esses programas têm uma população-alvo (usuários) que são parte do processo de organização e prestação das atividades, e que o produto final desses programas e serviços não é um objeto material, o que torna essa prática ainda mais complexa. Considerando essas observações, é recomendável que a avaliação seja sempre definida tendo como foco principal o resultado final que se espera alcançar no usuário.

O referencial teórico mais utilizado para avaliar serviços, sistemas ou programas de saúde é a concepção sistêmica de Donabedian, elaborada na década de 1980. Tal concepção é pautada na análise da estrutura, do processo e dos resultados obtidos (clínicos, humanísticos ou econômicos), dando uma verdadeira noção de todo o serviço, sistema ou programa que está sendo avaliado (DONABEDIAN, 1988).

Quando o processo de avaliação visa avaliar a introdução, expansão ou modificação de uma tecnologia sanitária, o estudo sistemático dos efeitos que podem ocorrer na sociedade foi denominado por Rozenfeld (1989) de avaliação de tecnologia de saúde (ATS).

As ATS são estudos complexos, que procuram sintetizar os conhecimentos produzidos a respeito das conseqüências para a sociedade, da utilização das tecnologias de atenção à saúde (promoção, prevenção e recuperação), com o objetivo de subsidiar decisões relativas à difusão e incorporação de tecnologias, particularmente as decisões relacionadas ao registro e ao financiamento de seu uso. As ATS supõem a análise de efeitos benéficos (eficácia e eficiência) e indesejados 
(colaterais e adversos) de uma tecnologia em condições ideais, a análise da efetividade e o exame comparativo da relação desses efeitos e do valor atribuído a esses efeitos, com os gastos correspondentes de recursos para diferentes alternativas tecnológicas. As ATS procuram também considerar as dimensões eqüidade, cultura e ética, sendo utilizadas para selecionar alternativas (tecnologias individuais ou conjuntos tecnológicos) para lidar com uma determinada necessidade ou problema de saúde (KRAUSS-SILVA, 2004).

Devido ao grande número e variedade de produtos e serviços de saúde disponibilizados no mercado nos últimos anos, as ATS são de grande importância no processo decisório de alocação de recursos, pois esses produtos e serviços nem sempre representam reais avanços na assistência sanitária. Por esse motivo, as ATS constituem o pilar da prática denominada Saúde Baseada em Evidências (DRUMMOND, 1987; ATALLAH, 2005).

Entre as tecnologias utilizadas em saúde estão os medicamentos, os dispositivos médicos, os procedimentos clínicos e cirúrgicos, e os sistemas organizacionais. Nestes últimos, são avaliados os resultados dos programas, ações e serviços assistenciais, em particular os custos (ROZENFELD, 1989).

Demonstrar que se justifica ou não os gastos dos sistemas de saúde com as novas tecnologias médicas é tarefa dos estudos de avaliação econômica (DRUMMOND et al., 1997; MOSEGUI, 2002).

Herrera e Diáz (2000) afirmam que, antes de se aceitar e difundir uma tecnologia dentro dos sistemas de saúde é necessário submetê-la a uma rigorosa avaliação econômica. Neste sentido, a administração sanitária deve adotar e fomentar a utilização de tal avaliação, assim como utilizá-la para ajudar que a tomada de decisões seja baseada em critérios mais objetivos. 
Segundo Mosegui (2002) a realização de uma avaliação econômica requer a realização prévia de outras avaliações. Primeiramente, é preciso ter informações quanto à eficácia de uma tecnologia sobre a saúde do indivíduo, evitando expô-lo a um risco potencial e evitando gastos desnecessários de tempo e de recursos com a avaliação econômica, caso a tecnologia avaliada não apresente benefícios para a saúde do paciente, não legitimando sua aplicação. Tais informações são obtidas mediante estudos clínicos em condições experimentais. Em seguida, se possível, é interessante conhecer como tal tecnologia se comporta em um cenário real, não controlado, através de informações sobre a efetividade da tecnologia em questão, para que se possa julgar se os resultados obtidos nos estudos controlados se repetem no cotidiano de uma determinada população. Destaca-se que a efetividade é freqüentemente menor que a eficácia (JOLICOEUR; JONES-GRIZZLE; BOYER, 1992; DEL CASTILHO, 1995; BOOTMAN; TOWSEND; MC GHAN, 1996).

É importante notar que a evidência científica sobre o efeito benéfico de uma tecnologia é essencial para a realização de avaliações econômicas. Sem tal evidência, a avaliação econômica em saúde perde o sentido porque não faz sentido prover serviços inefetivos, seja de forma otimizada (eficiente) ou não (DRUMMOND et al., 1997; HERRERA; DÍAZ, 2000). Portanto, é necessário que as evidências sobre eficácia e efetividade de determinada tecnologia, a respeito de parâmetros clínicos e humanísticos, sejam obtidas antes ou, ao menos, ao mesmo tempo em que uma análise econômica é desenvolvida (KRAUSS-SILVA, 2003).

Conforme Drummond et al. (1997), a avaliação econômica é a análise comparativa das ações alternativas, tanto em termos de custos, como de resultados, que tem como componentes básicos a identificação, a quantificação, a valoração e a comparação desses custos e resultados que estão sendo considerados. Esses 
componentes são características de toda avaliação econômica, incluídas aquelas relacionadas com serviços sanitários.

Tanaka e Melo (2004) definiram a avaliação econômica em saúde como o processo pelo qual os custos e conseqüências de determinada tecnologia sanitária são comparados com outras alternativas, verificando qual delas é capaz de proporcionar uma melhor relação custo-resultado ou uma utilização mais racional dos recursos disponíveis, não implicando, necessariamente, na redução de gastos.

A avaliação econômica em saúde apresenta instrumentos de análise capazes de quantificar recursos e produtos, e racionalizar a tomada de decisões. Ela lida com custos e conseqüências de tecnologias sanitárias, e as análises são sempre baseadas em escolhas, sendo que, a maioria dessas avaliações, tem uma perspectiva social, focada na otimização dos benefícios para a saúde da população, buscando o melhor resultado com o menor custo relativo (CAMPELL; ROLAND; BUETOW, 2000; MOSEGUI, 2002).

Devido a essas características, a avaliação econômica em saúde é um importante método para a tomada de decisão quanto à alocação de recursos, visando uma maior eficiência e impacto na sua utilização. É importante destacar que o aspecto mais relevante na avaliação econômica não são os custos, que são os insumos básicos, e sim os resultados alcançados com a aplicação destes (TANAKA; MELO, 2004).

Os países desenvolvidos têm adotado a avaliação econômica das intervenções sanitárias justificando que tais intervenções custam caro demais em relação aos resultados obtidos. Os países em desenvolvimento começaram a interessar-se pela avaliação econômica porque a carência de recursos exige que sejam alcançados melhores resultados com o pouco que possuem. Desta forma, a 
adoção de estratégias de contenção de custos e de avaliação de resultados das ações de saúde, representa um foco de atenção importante em todo o mundo, cenário que tem favorecido um ambiente fértil para a realização de estudos de avaliação econômica (VILLAR, 1995; VELÁSQUEZ, 1999; SECOLI et al. 2005). Na literatura nacional, todavia, verifica-se uma lacuna na produção de conhecimento neste campo (HARTZ; POUVOURVILLE, 1998).

A avaliação econômica em saúde é tratada de forma mais detalhada dentro da disciplina denominada Economia da Saúde e, por isso, será abordada com especial atenção no próximo tópico desse trabalho.

De acordo com Novaes (2000), a participação efetiva dos processos de avaliação nas grandes decisões políticas para a área da saúde no Brasil tem sido muito mais restrita do que o anunciado, além de haver, ainda, a carência de profissionais experientes no campo da avaliação. 


\subsection{ECONOMIA DA SAÚDE}

O cenário econômico dos sistemas de saúde vivenciado, atualmente, pela maioria das nações, é de escassez de recursos, de desperdício dos mesmos, de falta de incentivos para os diversos atores envolvidos, de incorporação de novas tecnologias em saúde sem critérios definidos e de grande variabilidade na utilização dos insumos e procedimentos sanitários. Diante desse cenário, faz-se necessária a utilização de métodos que auxiliem os gestores no processo de escolha entre alternativas disponíveis e que sejam capazes de mensurar o benefício para cada unidade de custo e estimar o retorno para a sociedade na incorporação de novas tecnologias. Esses métodos fazem parte da disciplina chamada economia da saúde e não representam uma forma de conter custos, mas de alocar os recursos escassos de forma racional, a fim de maximizar os benefícios para a sociedade (VIANNA; MESQUITA, 2003).

O crescimento dos gastos sanitários e a falta de recursos para o setor forçam a busca pelo equilíbrio entre os custos da prestação de cuidados em saúde e a respectiva efetividade e qualidade destes serviços. Trata-se, porém, de emprego equivocado do termo "economia da saúde" quando a escolha de uma intervenção ou tratamento é feita pelo seu menor custo, sem avaliar seus resultados terapêuticos. Sabe-se que a alocação de recursos tem grande influência na prestação de cuidados aos pacientes e que as medidas tradicionais de contenção de gastos nem sempre são sinônimos de melhoria na assistência à saúde. Não se deve pensar apenas em reduzir gastos, mas também na busca da melhor relação custo-resultado que essa quantia pode proporcionar. A redução dos gastos com produtos e serviços de saúde não é, em si, um objetivo válido. O que deve ser buscado é a obtenção 
dos mesmos resultados a um custo mais baixo, ou a melhoria dos resultados sem que se aumentem os custos (ZANINI et al. 2001; SILVA, 2003a; SECOLI et al., 2005).

Del Nero, em 1995, conceituou a economia da saúde como o "ramo do conhecimento que tem por objetivo a otimização das ações de saúde, ou seja, o estudo das condições ótimas de distribuição dos recursos disponíveis para assegurar à população a melhor assistência à saúde e o melhor estado de saúde possível, tendo em conta meios e recursos limitados".

De acordo com Campos (1985) apud Zucchi (1995)³ , a economia da saúde é "um modo de pensar que tem a ver com a consciência da escassez, com a imperiosidade das escolhas e com a necessidade dessas serem precedidas de avaliação dos custos, das conseqüências e dos aspectos éticos individuais e coletivos das alternativas possíveis, com vista a melhorar a repartição final dos recursos disponíveis".

Segundo a OMS (1976) apud Silva (2003a) ${ }^{4}$, a economia da saúde é estudada sob dois panoramas distintos:

O primeiro é o panorama macroeconômico que, geralmente, faz alusão ao setor saúde como um todo e à sua interface com outros setores sócio-econômicos como educação, segurança, transporte, habitação. Esse panorama de estudo é muito utilizado em nível de sistemas sanitários, pois seus resultados interessam à coletividade, o que torna muito complexos os estudos macroeconômicos em saúde.

O segundo panorama de estudo é o microeconômico que, por sua vez, refere-se ao estudo de cada um dos componentes de um sistema de saúde

\footnotetext{
${ }^{3}$ CAMPOS, A. F. C. Disciplina autônoma de economia da saúde. Escola Nacional de Saúde Pública. Lisboa, 1985. mimeo.

${ }^{4}$ Organización Mundial de la Salud. Economía aplicada a la sanidad. Cuadernos de Salud Publica. v. 64. 53p. Ginebra, 1976.
} 
(programa, serviço, organização, indivíduo). Esse é o panorama mais simples e também o mais explorado por pesquisadores brasileiros.

Segundo os economistas, os panoramas macro e microeconômico se referem à análise de agregados macroecômicos e à análise do comportamento individual, respectivamente.

O interesse das nações na racionalização dos gastos em saúde não é recente, assim como tampouco é recente o interesse por tecnologias que sejam capazes de diminuí-los e de melhorar a qualidade da atenção dispensada aos pacientes (MOSEGUI, 2002). Há relatos que citam o início da década de 1960 como a década na qual começaram os estudos em Economia da Saúde, matéria que só viria chegar e se consolidar em nosso país em meados da década de 1970 (ROBINSON, 1993; ZANINI et al. 2001).

No Brasil, têm sido publicados diversos trabalhos na área de avaliação econômica em saúde, mas os pesquisadores esbarram na ausência de dados sobre custos e resultados de intervenções. A utilização de dados de estudos internacionais, através da construção de metanálises, é uma alternativa para driblar esse empecilho, porém os resultados obtidos com tal prática podem não refletir a nossa realidade. Diferenças na estrutura de níveis sociopolíticos e econômicos ou nas características do sistema de saúde implicam em diferenças de acesso, de adesão, de continuidade do cuidado e de suporte social, entre outras. Essas diferenças podem modificar substantivamente as estimativas de custos e de resultados das tecnologias em nosso país (ZANINI et al., 2001; KRAUSS-SILVA, 2004).

Outras dificuldades relativas à nossa realidade são as falhas freqüentes no processo de manejo de tecnologias, associadas à falhas de planejamento e de 
gerência, determinando uma baixa efetividade das tecnologias em geral e ajudando, também, a modificar relações de custo-resultado encontradas em outros países. Pelos motivos expostos, é preciso entender a importância da avaliação econômica em saúde e estimular a adoção de métodos que possibilitem a construção de dados nacionais (ZANINI et al., 2001; KRAUSS-SILVA, 2004).

Comumente, a alocação de recursos para o setor saúde é feita através da disponibilização pelos países, durante a elaboração de seu orçamento anual, de uma parcela do produto interno bruto (PIB). Entretanto, na maioria dos países, a quantia monetária destinada ao setor é insuficiente, frente aos avanços tecnológicos que o afetam e ao aumento contínuo da demanda por atendimento (NOVAES, 2000; MARIN, 2003). Por isso, tais recursos devem ser distribuídos segundo critérios préestabelecidos, buscando-se a otimização de seu uso. Deve-se, ainda, considerar que o aumento de recursos para todo o setor saúde é, em geral, difícil de ser conseguido e, quando obtido, trata-se de processo vagaroso de negociação, em vista da oposição de outros setores da vida nacional como educação, transportes, forças armadas, que disputam os mesmos recursos. Concedê-los a uma área significa não alocá-los em outras que, naturalmente, se oporão a semelhante procedimento, sendo difícil determinar qual área deve ser sacrificada (PEREIRA, 1995a).

No interior do setor saúde, o mesmo raciocínio também se aplica. Ceder recursos para um tipo de atividade significa não alocar os mesmos recursos para outras atividades. A alocação de insumos é um processo consciente e político de decisões, porém, há um outro aspecto, não menos importante, que influencia o emprego desses insumos: o uso desnecessário em uma direção impede o uso adequado dos mesmos recursos financeiros em outra direção, já que o montante 
total dedicado à saúde é relativamente constante. Em suma, há uma relação complexa entre usos de serviços e alocação de recursos no interior do sistema de saúde, mesmo que os profissionais de saúde não estejam atentos para essa associação, na prática do dia-a-dia, quando prescrevem os diversos métodos de diagnóstico e tratamento, ou decidem as formas de lidar com os seus pacientes. Este cenário também é visualizado nos sistemas de saúde privados, porém em menor intensidade (PEREIRA, 1995a; HERRERA; DÍAZ, 2000).

Em saúde, não fosse a presença de uma tensão natural e constante entre o que o sistema pode oferecer e o que o público (população) espera dele, não haveria essa lacuna e todas as ações demandadas poderiam ser ofertadas, sem necessidade de restringir e racionalizar as intervenções, nem de considerar as questões relativas à eficiência dos serviços. Os orçamentos, entretanto, são limitados e, quando se opta por uma atividade, é negado o uso desse recurso em outra. É necessário, portanto, conhecer os resultados e os custos de atividades e programas sanitários, para que, através da aplicação de análises econômicas, se possam fazer as escolhas adequadas, visando uma distribuição racional dos recursos disponíveis, em prol do conjunto da sociedade (JOLICOEUR; JONESGRIZZLE; BOYER, 1992; DEL CASTILHO, 1995; VELÁSQUEZ, 1999).

Segundo os autores Jolicoeur; Jones-Grizzle e Boyer (1992), as análises econômicas em saúde são compostas por oito etapas:

1. Definição do problema de natureza econômica;

2. Determinação da perspectiva do estudo;

3. Determinação de todas as alternativas e desfechos possíveis;

4. Seleção do tipo de análise econômica apropriado;

5. Identificação de quais itens serão incorporados na análise de custo; 
6. Identificação de custos e resultados;

7. Realização de cálculos para obtenção dos resultados;

8. Realização de análise de sensibilidade.

Esta estruturação proposta por Jolicoeur; Jones-Grizzle e Boyer (1992), quando seguida, proporciona maior credibilidade aos resultados das avaliações econômicas realizadas.

A avaliação econômica em saúde é uma ferramenta de apoio à decisão, utilizada para estabelecer critérios sobre o uso de recursos na área, porém qualquer decisão a ser tomada deve ser precedida da observação de princípios éticos, individuais e coletivos. Portanto, é importante medir e comparar os recursos alocados, mas, principalmente, os benefícios alcançados com um determinado programa, serviço ou ação de saúde (KOZMA; REEDER; SCHULZ, 1993; DEL CASTILHO, 1995; VELÁSQUEZ, 1999; CASTRO, 2002; FRIAS-BULHOSA, 2004).

A noção de custos (recursos alocados) e de resultados (benefícios alcançados) é relativa, e depende, principalmente, da ótica pela qual o objeto de estudo é avaliado, geralmente a do pagador da intervenção (paciente, provedor de serviços, plano de saúde, sociedade). Desta forma, determinado desfecho da avaliação econômica pode apresentar relação custo-resultado favorável para alguém e desfavorável para outrem. A este desenvolvimento "customizado" da avaliação econômica dá-se o nome de perspectiva ou ponto de vista do estudo e sua definição é de fundamental importância para direcionar a coleta e análise de dados da pesquisa avaliativa (FERRAZ, 1996; MALEK, 1996; BASSKIN, 1998; BEVILÁQUA, 2001).

Por existirem potenciais conflitos de interesse entre os vários atores participantes do sistema de saúde, quanto aos desfechos das avaliações 
econômicas, geralmente, adota-se, sempre que possível, a perspectiva da sociedade para a realização dessas avaliações. Quando uma avaliação econômica é realizada sob a perspectiva da sociedade, todos os atores afetados por uma intervenção são considerados e todos os resultados e custos que dela resultam são levados em consideração, independentemente de quem financiou a avaliação, de quem se beneficiou ou não da intervenção ou sobre quem recaíram os custos da mesma. A adoção da perspectiva de análise da sociedade, portanto, é a que melhor reflete o princípio da equidade, balizador das principais decisões de saúde (MOSEGUI, 2002; VIANNA e MESQUITA, 2003; KRAUSS-SILVA, 2003). Entretanto, segundo Ferreira e Loureiro (2006), atualmente, a maioria das análises econômicas em saúde é feita sob a ótica do serviço, sendo poucas as análises realizadas sob a ótica do paciente ou da sociedade.

Para que uma avaliação econômica seja considerada completa é necessário que a mesma contemple duas condições: avaliar simultaneamente os custos e os resultados dos objetos de estudo e realizar comparação entre duas ou mais alternativas possíveis (em alguns casos, está implícito que uma das alternativas é não se fazer intervenção). Quando essas condições são contempladas, são possíveis quatro tipos de análise: custo-minimização (ACM), custo-efetividade (ACE), custo-benefício (ACB) e custo-utilidade (ACU) (DRUMMOND, 1991; DRUMMOND et al., 1997; CASTRO, 2002).

Caso alguma das condições citadas acima não seja atendida, haverá uma avaliação econômica incompleta, classificada em um dos seguintes tipos (DRUMMOND et al., 1997; CASTRO, 2002):

- Descrição de custos: quando não é feita a comparação entre alternativas e apenas os custos são examinados; 
- Descrição de resultados: quando não é feita a comparação entre alternativas e apenas as conseqüências são examinadas;

- Descrição de custos e de resultados: quando não é feita a comparação entre alternativas e os custos e conseqüências são examinados;

- Avaliação de resultados: quando é feita a comparação entre alternativas e não são avaliados os custos;

- Avaliação de custos: quando é feita a comparação entre alternativas e não são avaliados os resultados.

Na maioria dos estudos realizados na área da saúde, não são feitas avaliações econômicas completas, e sim, estudos parciais (avaliações econômicas incompletas). Esses estudos representam etapas intermediárias para a compreensão dos custos e dos resultados de um determinado programa, serviço ou ação de saúde e não são capazes de responder às questões relativas à eficiência no uso de recursos (CASTRO, 2002). Essas respostas são então fornecidas pelas avaliações econômicas completas, onde cada tipo de análise é utilizado para avaliar, sob um determinado aspecto, a relação entre os resultados e os custos das intervenções.

A análise custo-minimização é o tipo de avaliação econômica mais simples e mais limitada. Esse tipo de avaliação compara os custos de dois ou mais procedimentos alternativos, os quais buscam alcançar resultados clínicos idênticos. Neste tipo de estudo, supõe-se que os efeitos sobre a saúde do paciente, proporcionados por todas as alternativas comparadas, sejam os mesmos (SILVA; FORMIGLI, 1994; UGÁ, 1995; DRUMMOND, et al., 1997; GONZÁLEZ, 1999; VELÁSQUEZ, 1999). As ACM têm o objetivo de identificar a alternativa que possui o volume total de custos mais reduzido, sendo sua principal vantagem a simplicidade 
de aplicação, porém sua aplicação é restrita devido ao reduzido número de terapias com efeitos similares (UGÁ, 1995).

A análise custo-efetividade é a forma de avaliação econômica mais utilizada no setor saúde. Ela permite comparar distintos programas destinados a melhorar um determinado parâmetro clínico e, conseqüentemente, identificar o programa que apresenta o menor custo por unidade de impacto relacionada ao parâmetro clínico avaliado. Nesse tipo de avaliação, assim como nas ACM, os custos são expressos em unidades monetárias e os resultados em unidades físicas de efetividade (nível de milímetros de mercúrio da pressão arterial, número de vidas salvas, casos detectados, número de reações adversas a medicamentos prevenidas), denominadas indicadores de resultados (SILVA; FORMIGLI, 1994; UGÁ, 1995; DRUMMOND et al., 1997; COWPER et al.1998; GONZÁLEZ, 1999; VELÁSQUEZ, 1999; FERREIRA; LOUREIRO, 2006).

De acordo com Prades (1998), as medidas de resultados podem ser divididas em dois tipos: indicadores intermediários e finais de efetividade. Em geral, a escolha por um ou outro indicador de efetividade irá depender dos objetivos propostos pela avaliação, bem como do tempo do estudo destinado a medir as variações nas conseqüências sobre o estado de saúde dos indivíduos. Em pacientes aidéticos, a redução da carga viral é um exemplo de indicador intermediário, no entanto, essa diminuição promove um aumento na esperança de vida desses enfermos que é um exemplo de indicador final de efetividade.

É amplamente reconhecido que a ACE possui a potencial vantagem, em relação à análise custo-benefício, descrita em seguida, de não exigir que os resultados de um programa de saúde sejam expressos em termos monetários, procedimento este ética e metodologicamente questionável (OLSEN; SMITH; 
HARRIS, 1999). Entretanto, alguns autores, como Kenkel (1997), Brouwer e Koopmanschap (2000) e Weinstein e Manning Junior (1997), apontam para a ausência, na metodologia da ACE, de um patamar mínimo a partir do qual os custos de um programa específico passariam a ser compensados pelos seus benefícios, uma vez que os custos e os resultados das intervenções são apresentados sob a forma de unidades de medida distintas entre si.

A análise custo-benefício faz relação entre os custos associados a determinado tratamento de saúde e os benefícios monetários obtidos com este tratamento. Neste tipo de análise, tanto os custos, como as conseqüências de uma intervenção, são expressos em termos monetários. Isso exige que os resultados das alternativas a serem comparadas sejam monetarizáveis, o que determina um número reduzido de $\mathrm{ACB}$ realizadas, pois, nem sempre, os impactos de intervenções sanitárias podem ser mensurados de forma monetária. Esse tipo de análise, por mensurar os resultados em unidades monetárias, permite a comparação entre quaisquer projetos, programas ou ações sanitárias e, também, a comparação com a opção de não se fazer nada, ou seja, não implementar um projeto, programa ou ação alternativos. A ACB é a que fornece uma visão mais apurada sobre o retorno monetário advindo de determinado investimento em saúde e, por isso, são, atualmente, as mais procuradas pelos gestores sanitários, o que se explica pelo momento difícil que passa a economia mundial, afetando o segmento saúde e despertando grande interesse em estudar possíveis reduções de gastos com medicamentos, materiais e processos (SILVA; FORMIGLI, 1994; UGÁ, 1995; DRUMMOND et al., 1997; GONZÁLEZ, 1999; VELÁSQUEZ, 1999; BEVILÁQUA, 2001; MOTA; FERNANDES; COELHO, 2003; FERREIRA; LOUREIRO, 2006). 
Segundo Drummond (1991), na verdade, as ACB que são realizadas, geralmente, se concentram naquelas conseqüências que são relativamente fáceis de serem estimadas monetariamente, levando em consideração a economia de recursos proporcionada pela melhoria do estado de saúde do paciente.

Uma alternativa para "driblar" a dificuldade de mensurar de forma monetária alguns resultados em saúde, é a utilização da técnica denominada willingness-to-pay ou, em português, "disposição a pagar". Essa técnica vem se tornando, ao longo dos últimos anos, a mais aceita entre os defensores da ACB para se mensurar benefícios de saúde em termos monetários. Essa medida está baseada nos juízos dos próprios indivíduos em relação ao valor monetário que atribuem à melhoria do seu estado de saúde.

A disposição a pagar reflete o comportamento das pessoas em função de sua condição socioeconômica e de seu estado de saúde no momento da entrevista, de acordo com a necessidade das mesmas em utilizar a tecnologia sanitária que está sendo avaliada. Vale salientar que um indivíduo com um nível de renda mais elevado ou com uma pior condição de saúde estará disposto a pagar um preço maior por determinada tecnologia que um outro em situação econômica ou sanitária inferior. Essas situações geram um problema de validade dos resultados obtidos por esse método de mensuração dos resultados de intervenções sanitárias (HERRERA; DIÁZ, 2000).

Outro tipo de avaliação econômica utilizado pela área da saúde é a avaliação tipo custo-utilidade, que compara diferentes intervenções sanitárias, nas quais os custos são expressos monetariamente e os resultados são expressos em termos de "anos de vida perdidos ajustados pela incapacidade" do inglês disability-adjusted life years (DALY) ou em termos de anos de vida ajustados pela qualidade (AVAQ) ou 
QALY do inglês quality-adjusted life years. A utilidade de um tratamento se refere aos benefícios trazidos ao paciente em termos de qualidade de vida relacionada à saúde. O AVAQ é uma medida de utilidade que relaciona quantidade (variação na mortalidade) e qualidade de vida (variação na morbidade) de um paciente. A construção de um AVAQ envolve um estado de saúde valorizado pelo paciente, multiplicado por um período de tempo no qual o indivíduo permanece nessa situação de saúde. Dessa forma, trata-se de uma ponderação dos anos de vida por um fator de qualidade quantitativo, obtido a partir de instrumentos de medida da qualidade de vida, relacionado com a saúde das pessoas, nos quais o paciente expressa sua percepção sobre vários aspectos ou dimensões da sua saúde. Assim, o número de anos de vida ajustados por qualidade de vida, representa a sobrevida relativa a uma alternativa expressa em número de anos sobrevividos com saúde (SILVA; FORMIGLI, 1994; UGÁ, 1995; GARBER et al., 1996; DRUMMOND et al., 1997; GONZÁLEZ, 1999; VELÁSQUEZ, 1999; MOTA, 2003; MOTA; FERNANDES; COELHO, 2003; SCHMIDT; DUNCAN, 2003).

Os instrumentos de medida da qualidade de vida podem ser genéricos ou específicos, os quais permitem comparar diferentes intervenções de saúde. Os genéricos, normalmente, são instrumentos multidimensionais, que abordam as funções social, emocional, psicológica, mental e física, e são utilizados na população em geral ou em grupos concretos de indivíduos. Os instrumentos específicos são empregados para analisar a qualidade de vida relacionada com a saúde em determinadas enfermidades ou em grupos específicos de pacientes, onde se incluem apenas os aspectos importantes de cada enfermidade ou de cada grupo. Suas vantagens em relação aos instrumentos genéricos são a sua alta sensibilidade (capacidade do instrumento detectar algo que existe, o que implica, também, em sua 
capacidade de não fornecer resultados falsamente negativos) e a sua especificidade (capacidade do instrumento não detectar algo que não existe, o que implica, também, em sua capacidade de não fornecer resultados falsamente positivos), já sua principal desvantagem é a impossibilidade de ser utilizado para comparar diferentes doenças ou diferentes grupos populacionais (PEREIRA, 1995; CICONELLI, 1997; FLECK, 2000; LIMA, 2002).

Zanini et al. (2001) chamam atenção para o fato de que, independente do tipo de análise econômica empregado no processo avaliativo, pequenas variações nos custos e nos resultados das intervenções podem alterar os resultados da avaliação econômica, modificando a relação custo-resultado obtida em avaliações anteriores. Em virtude disso, deve ser feita uma análise de sensibilidade para verificar a consistência dos resultados, ou seja, o quanto eles permanecem estáveis frente a modificações dos dados de origem: custos e resultados.

A análise de sensibilidade do estudo é a última etapa a ser realizada em uma avaliação econômica em saúde e é imprescindível, visto que, algumas variáveis empregadas na avaliação econômica de uma tecnologia de saúde podem adotar diferentes valores em diferentes realidades em que essa mesma tecnologia é empregada (diferentes países, instituições de saúde, etnias, classes sociais), e que, os valores das referidas variáveis podem não serem conhecidos com total certeza (informação estatística pouco confiável), sendo necessário testar até que ponto as oscilações nas variáveis mais relevantes para o resultado do estudo podem afetar as conclusões do mesmo. (JOLICOEUR; JONES-GRIZZLE; BOYER, 1992; VILLAR, 1995; BOOTMAN; TOWSEND; MC GHAN, 1996; AGRO et al., 1997; VELÁSQUEZ, 1999). 
Para a realização de uma análise de sensibilidade, devem ser selecionadas importantes variáveis de custos e de resultados (taxa de desconto, número de atendimentos, índice de qualidade de vida, custo total da intervenção), referentes à tecnologia a ser avaliada, para que, dentro de critérios plausíveis, estas variáveis tenham seus valores modificados e, então, sejam recalculados os resultados da avaliação. Caso as modificações realizadas nas variáveis selecionadas não produzam mudança nos resultados originais da avaliação, o estudo será considerado "robusto", ou seja, pouco sensível às oscilações nos valores das variáveis, o que dá credibilidade ao mesmo (DEL CASTILHO, 1995; PEREIRA, 1995a; VILLAR, 1995; BOOTMAN; TOWSEND; MC GHAN, 1996).

O emprego de técnicas, como a análise de sensibilidade e o uso de modelos epidemiológicos nas avaliações econômicas em saúde são fundamentais para a elaboração do desenho metodológico do estudo e para a análise dos resultados das avaliações. Neste aspecto, é da maior relevância que gestores, prestadores de serviços e profissionais do setor conheçam suficientemente os fundamentos básicos da epidemiologia para adoção da avaliação econômica como ferramenta em sua prática profissional (SILVA, 2003a).

A aplicação de princípios e métodos epidemiológicos na prática sanitária diária é denominada epidemiologia clínica. A disciplina trata do método usado por clínicos das diversas profissões da saúde como medicina, enfermagem, fisioterapia e farmácia, para avaliar os processos e os resultados de suas atividades (SILVA, 2003a).

De acordo com Vianna e Mesquita (2003) uso da epidemiologia clínica é condição sine qua non para a acurácia (validade) da análise econômica em saúde. 
A justificativa para o desenvolvimento da epidemiologia clínica é que a tomada de decisão na escolha de intervenções clínicas, quanto a processos e resultados (clínicos, humanísticos e econômicos), deve ser baseada em princípios científicos seguros, pois a decisão clínica, diagnóstica ou terapêutica, ocupa o centro do cenário sanitário, no qual, atualmente, a maior parte dos recursos são alocados através das milhares de decisões clínicas que são tomadas em condições de incerteza (SILVA, 2003a).

Hoje, a multiplicidade de intervenções, cada uma delas com diferentes potenciais de benefício, risco e custo, está exigindo respostas mais seguras, baseadas em investigações sistematizadas (pesquisas) sobre questões clínicas específicas. Em contraposição à experiência clínica (investigação nãosistematizada), essas pesquisas exigem rigor metodológico no controle para vieses típicos do contexto clínico de investigação. Entre outros aspectos, essas pesquisas apresentam objetivos e hipóteses definidos a priori: padronização de medidas e definição de desfechos clínicos, busca ativa de participantes que não retornam ao serviço e expressão quantitativa dos benefícios, riscos e custos associados a sua aplicação clínica (SCHMIDT; DUNCAN, 2003).

Pereira (1995a) afirma que a avaliação de tecnologias sanitárias representa uma grande área de aplicação dos conceitos e métodos da epidemiologia, ao lado das doenças infecciosas e das não-infecciosas. Dentre essas três áreas, a avaliação tecnológica em saúde é a de aplicação mais recente da epidemiologia e, talvez por isso, seus contornos ainda não estejam inteiramente delineados e estruturados, porém ela pode ser utilizada na constituição de métodos de avaliação de serviços, técnicas, programas e ações de saúde, fornecendo muitos dos dados e das interpretações a serem utilizados como suporte nas decisões a serem tomadas, no 
âmbito do planejamento, da alocação de recursos e da organização de serviços de saúde (PEREIRA, 1995a).

No processo de avaliação em saúde, podem ser utilizados os mesmos princípios e métodos da pesquisa etiológica de doenças, ou seja, os mesmos métodos epidemiológicos que se destinam a determinar o papel dos fatores de risco na gênese da doença. Entretanto, é necessário fazer adaptações nos referidos métodos para adequá-los a este tema e ao diferente contexto em que serão empregados: a elucidação da possível relação causal entre a utilização de determinado processo de atenção à saúde ou a aplicação de um recurso (material, humano ou financeiro) e os resultados, expressos sob a forma de algum indicador de saúde (PEREIRA, 1995a). Como exemplo, cite-se a associação causal entre a prestação de serviço de ATENFAR e seu impacto sobre a relação custo-efetividade, custo-minimização, custo-utilidade ou custo-benefício do tratamento sanitário de uma população que receba tal serviço.

Para melhor conhecer a saúde da população, os fatores que a determinam, a evolução do processo da doença e o impacto das ações propostas para alterar o seu curso, os homens de ciência desenvolveram numerosos métodos de investigação epidemiológica. Como conseqüência, atualmente, há muitos métodos à disposição dos pesquisadores, sendo que para uma dada situação ou momento, um deles poderá ser mais adequado do que outro. Cada qual tem os seus aspectos positivos e suas limitações, de modo que, conhecê-los, possibilita prever as facilidades e as dificuldades que serão encontradas durante sua utilização, apontando, dessa forma, qual é o método mais indicado para a investigação que se deseja realizar (PEREIRA, 1995a). 
Os referidos métodos epidemiológicos possuem duas classificações principais. Eles podem ser classificados como descritivos, que estudam a distribuição de um evento em determinada população, ou como analíticos, que buscam comprovar se uma associação observada entre dois fatores é resultante do simples acaso (relação não-causal) ou se existe relação entre causas e efeitos objetos de estudo (relação causal).

Para responder se a associação observada em um estudo é causal ou nãocausal, utilizam-se métodos estatísticos que testam a hipótese de não-causalidade entre exposição e efeito, denominada hipótese de nulidade $\left(\mathrm{H}_{0}\right)$, contra a hipótese alternativa $\left(\mathrm{H}_{1}\right)$, de existência de causalidade. Se a resposta for favorável a $\mathrm{H}_{0}$, essa hipótese não será rejeitada, e a conclusão será pela não-existência de causalidade. Caso contrário rejeita-se $\mathrm{H}_{0}$, sendo provável que a associação em estudo não seja devida ao acaso (DAL FABBRO, 2005).

A realização de avaliações econômicas em saúde visa responder como uma determinada tecnologia influencia nos custos de tratamentos de saúde e em seus resultados. Neste questionamento estão contidas duas hipóteses, onde a associação causal entre a utilização da tecnologia e seu impacto sobre a relação custo-efetividade, custo-minimização, custo-utilidade ou custo-benefício do tratamento de uma população que usufrua de tal tecnologia deva ser testada:

$\mathrm{H}_{0}=\mathrm{A}$ utilização de determinada tecnologia sanitária não modifica a relação entre custos e resultados de tratamentos de saúde quando comparada à utilização de uma outra tecnologia;

$\mathrm{H}_{1}=\mathrm{A}$ utilização de determinada tecnologia sanitária melhora ou piora a relação entre custos e resultados de tratamentos de saúde quando comparada à utilização de uma outra tecnologia. 
Quando, em um estudo, existe uma ou mais hipóteses a serem testadas, o modelo de investigação indicado para verificar essas hipóteses é o estudo analítico, no qual o efeito ou resultado é chamado de variável dependente e o fator causal suspeito é chamado de variável independente. Havendo comprovação da correlação causa-efeito entre essas variáveis, pode-se afirmar, desde que não haja vieses ou até que outro estudo obtenha resultado divergente, que a ocorrência do efeito (variável dependente) depende da influência da possível causa descrita (variável independente) (PASSOS; RUFFINO-NETTO, 2005a). Os vieses, também chamados de erro sistemático, vício, tendenciosidade, desvio, deturpação, distorção ou bias (do inglês), se referem a erros sistemáticos, não devidos ao acaso, inadvertidamente introduzidos em qualquer fase de um estudo, que podem levar a associações causais errôneas entre as variáveis que estão sendo observadas e, caso não sejam evitados, poderão comprometer o estudo (PEREIRA, 1995a; HADDAD, 2004).

Os estudos analíticos são subdivididos em experimentais e observacionais e caracterizam-se pela presença de um grupo-controle, não-exposto ao possível fator causal, formado simultaneamente com o grupo de estudo, exposto ao possível fator causal, que serve para a comparação dos resultados. A representação de um estudo analítico com apenas dois grupos (expostos e não-expostos a um determinado fator) tem o objetivo de simplificar o entendimento do modelo de estudo, porém não há impedimentos para que um estudo desse tipo seja utilizado para testar o papel de múltiplos fatores no aparecimento de um determinado resultado (PEREIRA, 1995a; HADDAD, 2004).

Uma outra maneira de estruturar um estudo experimental é a utilização de um grupo autocontrole, especialmente, em alguns tipos de experimento em que o critério de avaliação do resultado, pelo próprio participante, for bastante subjetivo, 
como dados relacionados à qualidade de vida deste. Neste caso, é preferível utilizar o próprio participante como controle de si mesmo, isto é, o participante, inicialmente, será exposto a um determinado fator ou placebo e, depois de um determinado tempo, suficiente para eliminar os efeitos da referida exposição, será exposto a um outro fator ou a um placebo, ou seja, o mesmo indivíduo será caso e controle.

No modelo de investigação autocontrole, é importante que se faça a casualização da exposição (determinar a variável independente e a variável dependente), pois a ordem de exposição pode influenciar os resultados, por existir, em geral, uma tendência dos participantes do estudo a valorizarem mais os resultados da primeira exposição, o que poderia levar a erros na análise e conclusão da pesquisa. Estudos desta natureza são chamados estudos com controles históricos ou estudos com um só grupo experimental e possuem a vantagem de demandarem menor número de indivíduos para compor o estudo, porém, esse tipo de estruturação demanda maior tempo de acompanhamento, pois os participantes do estudo deverão ser monitorados em dois momentos distintos, ao contrário da estruturação que utiliza um grupo controle simultâneo ao grupo intervenção, a qual demanda um maior número de participantes para o estudo, mas possui a vantagem de realizá-lo em um menor espaço de tempo, perdendo menos pacientes por não adesão do que nos estudos com controles históricos (REY, 1987; PEREIRA, 1995a).

As avaliações econômicas em saúde, sejam elas auto-controle ou não, nas quais o grupo controle e o grupo experimental são acompanhados em épocas distintas, devem ter seus resultados ponderados através de um método de equiparação temporal de custos. O método mais amplamente aceito de comparação de custos e conseqüências que ocorrem em tempos diferentes é equipará-los aos valores de hoje (valores presentes). Esta abordagem tem o efeito de dar aos custos 
e conseqüências que ocorrem no presente um peso maior na análise do que àqueles que ocorrem no futuro. A suposição-chave nesta abordagem é a escolha da taxa de desconto. Entretanto, apesar de existir uma boa quantidade de estudos econômicos sobre o assunto, as discordâncias começam na determinação do valor dessa taxa. A maioria dos economistas concorda que a taxa de desconto deve ser superior a zero, sendo que, na prática, o que se vê na literatura, geralmente, são avaliações econômicas em saúde com taxas de desconto variando, subjetivamente, entre 2\% e 10\% (DRUMMOND, 1991; UGÁ, 1995; CAIRNS, 2001; COUTTOLENC; ZUCCHI, 2002; PEREIRA, 1995a; VIANNA; MESQUITA, 2003).

Segundo Pereira (1995b), o valor de referência para a taxa de desconto na área da saúde é de 5\%, porém, devido à faixa de variação encontrada na literatura, é aconselhável ensaiarem-se vários resultados com diferentes valores de taxa, a fim de realizar uma análise de sensibilidade dos resultados da análise econômica.

A definição da taxa de desconto reflete a preferência temporal do pesquisador em realizar a análise econômica e nada tem a ver, como por vezes se supõe, com a inflação ou qualquer índice de preços (PEREIRA, 1995a).

Nos estudos experimentais ou de intervenção, o próprio investigador seleciona os participantes do estudo e determina a exposição ou não de indivíduos a determinado fator que é julgado capaz de proporcionar um determinado efeito e, depois de certo tempo, verifica a ocorrência ou não do efeito nos grupos de indivíduos expostos e não expostos. Ao realizar a alocação de indivíduos nos grupos, o investigador procura controlar o maior número possível de vieses. Um método para controlar a interferência de vieses nos resultados dos estudos é a randomização da amostra. Este método é empregado para distribuir homogeneamente entre os grupos caso e controle, fatores que possivelmente 
interfeririam nos resultados do estudo. O objetivo de tal distribuição é anular a influência dos referidos fatores, evitando que um grupo receba uma "maior carga" desses fatores que o outro, formando grupos com características semelhantes. Essa homogeneização é conseguida, necessariamente, por meio de uma alocação casual e probabilística de indivíduos ou conglomerados nos grupos caso e controle, isto é, é dado a cada participante a mesma probabilidade de pertencer a cada um dos grupos formados para o estudo (PASSOS; RUFFINO-NETTO, 2005b; HADDAD, 2004).

Se os participantes estiverem todos disponíveis no início da pesquisa, podese realizar uma alocação casual e probabilística, enumerando-se o total (n) de indivíduos de 1 (um) até n e sorteando-se, através de processo aleatório (papéis numerados, tabelas de números casuais informatizadas ou não) uma amostra com (n') indivíduos para o grupo intervenção e outra com (n") indivíduos para o grupo controle. Entretanto, na maioria dos experimentos clínicos, os pacientes não estão todos disponíveis no início da investigação. Eles vão surgindo à medida que a investigação prossegue, como os pacientes atendidos em ambulatório, em unidades de emergência, em pequenas enfermarias. Nesses casos, a alocação casual e probabilística de cada paciente em determinado grupo é feita da seguinte forma: determina-se, previamente, através dos processos aleatórios citados acima, a qual grupo pertencerá cada indivíduo que entrar no estudo, de acordo com sua ordem de entrada (primeiro, segundo, terceiro e daí por diante) (HADDAD, 2004).

Também chamada de aleatorização ou casualização, a randomização constitui a grande vantagem dos estudos experimentais sobre os observacionais, embora possam ser empreendidas investigações experimentais sem recorrer à randomização para formar os grupos de estudo e controle. Segundo Pereira (1995a) e Haddad (2004), o estudo experimental randomizado é o melhor entre todos os 
métodos de investigação utilizados em epidemiologia, pois é o que produz evidências mais diretas e inequívocas para esclarecer uma relação causa-efeito entre dois eventos ao igualar os diferentes grupos no que diz respeito às suas características gerais, sendo as diferenças observadas entre eles após a intervenção, provavelmente, devidas a ela. Por esses motivos a comparação entre tecnologias, de modo a julgar qual delas obtém melhores resultados, é feita, em termos ideais, através de estudos desse tipo.

Embora os estudos randomizados sejam os mais adequados para inferir causalidade, eles, geralmente, são complexos, demorados e de custo elevado. Outro problema é que quando o experimento é realizado com amostras reduzidas, mesmo a alocação casual e probabilística pode não garantir confiabilidade de que os grupos serão comparáveis em relação a algumas variáveis que, eventualmente, poderão interferir nos resultados. Nesses casos, pode-se conseguir homogeneidade dos grupos por meio de um processo conhecido como estratificação, pelo qual a alocação dos indivíduos em grupo de estudo ou de controle é feita dentro de estratos previamente definidos, criados com base naquelas variáveis potencialmente capazes de interferir nos resultados. Como exemplo, se eventuais diferenças entre os grupos em relação às variáveis idade, classe social e nível de instrução forem consideradas como capazes de influenciar os resultados do experimento, e esse for conduzido com reduzido número de participantes, de maneira a não garantir homogeneidade por meio da tradicional alocação casual e probabilística, preparamse estratos relativos a idade, classe social e nível de instrução.

Uma vez iniciado o experimento, os participantes que satisfizerem os critérios de inclusão deverão ser alocados no grupo de estudo ou de controle dentro do estrato que lhes corresponde. No caso de adentrar o estudo um indivíduo portador 
de um fator passível de gerar confundimento nos resultados, ele será inicialmente sorteado quanto ao grupo que deverá participar. Caso o resultado do sorteio tenha apontado para o grupo dos controles, automaticamente um segundo indivíduo, portador do mesmo fator, que adentrar o estudo, será alocado no grupo dos casos e vice-versa. Em seguida, repete-se o experimento, de tal maneira que, dentro de cada estrato, exista o mesmo número de indivíduos, portadores do fator passível de gerar confundimento, alocados nos grupos caso e controle. O que se faz, na realidade, é uma alocação também casual e probabilística, porém realizada dentro de estratos previamente definidos.

Por motivos práticos, a maior parte dos estudos que utilizam amostras estratificadas usa um único critério para formar tais estratos, que, por esse motivo, são chamados de estratos univariados. Entretanto, apesar da praticidade proporcionada ao estudo pela formação de estratos univariados, estes não oferecem ao mesmo um nível satisfatório de validade (capacidade de produzir resultados semelhantes ou próximos ao verdadeiro) e um bom grau de precisão (capacidade para reproduzir resultados semelhantes quando o estudo é repetido, em condições semelhantes, desde que o pesquisador desconheça os resultados anteriores da aplicação do mesmo). Ao contrário, estudos que utilizam múltiplos critérios para estratificar a amostra, formando estratos denominados multivariados, proporcionam as referidas vantagens, apesar de tornar mais difícil a realização do estudo devido à maior complexidade da estratificação (PEREIRA, 1995a; HADDAD, 2004).

Para a realização de avaliações econômicas do impacto da atividade de ATENFAR, a estratificação pode ser feita por nível de instrução que, geralmente, é determinado pelo número de anos de estudo ou pelo grau de escolaridade do indivíduo, sendo que este último oferece melhor entendimento e definição; por nível 
de renda, determinado pelo montante financeiro ganho mensalmente pelo indivíduo; pela ocupação do indivíduo, determinada pelo tipo de atividade laboral que este exerce; por sexo, visto que mulheres, geralmente, têm maior comprometimento e adesão a tratamentos de saúde; por etnia; por estado civil; por existência de comorbidades, por tempo de diagnóstico da doença; por existência de antecedentes familiares ou por fatores associados ao estilo de vida, como hábitos alimentares, nível de atividade física, vícios (fumo, álcool, drogas ilícitas), hábitos sexuais, nível de estresse. Estes estratos são adequados visto que a ATENFAR, por ser um serviço desenvolvido com base na troca de informações entre o paciente e o farmacêutico, tende a ser mais efetivo quanto maior for o nível de instrução do paciente; que conhecimentos adquiridos permitem que o indivíduo lide melhor com sua enfermidade e eleja modos de vida mais saudáveis; que um maior nível de renda permite maior acesso a alimentos, instrução, tratamentos de saúde, terapias complementares e que a ocupação do indivíduo lhe permite ter maior ou menor afinidade pelo serviço de ATENFAR (PEREIRA, 1995a; LYRA JÚNIOR, 2005).

A seleção dos participantes de um estudo experimental a partir da população de estudo, deve obedecer a critérios de inclusão e de exclusão bem definidos e claramente explicitados que atendam aos objetivos do estudo. Naturalmente, a adoção desses critérios refletirá na generalização externa do experimento, limitandoa de acordo com a extensão maior ou menor dos critérios de seleção dos participantes (PASSOS; RUFFINO-NETTO, 2005b).

Para que os resultados obtidos na amostra de estudo possam ser generalizados para a população de referência, aquela deverá ser representativa dessa última, ou seja, ter suas características gerais e apresentar uma incidência do evento esperado que seja compatível com seu tamanho. O tamanho amostral do 
experimento deve ser definido através de regras de amostragem estatística, considerando o tamanho da população de referência, de maneira a permitir inferências dos resultados obtidos para a população.

Muito embora a seleção de indivíduos participantes de um estudo e o controle sobre a alocação dos mesmos em grupos caso e controle, por parte do investigador, represente um avanço metodológico importante, estas ações são fatores limitantes ao uso generalizado da metodologia experimental com seres humanos, em função de razões éticas que inviabilizam o uso de tal modelo em inúmeras situações. Em virtude da existência dessas razões, regras muito rígidas devem ser seguidas na execução de um projeto experimental, cabendo aos comitês de ética em pesquisa um pronunciamento sobre sua adequação.

Motivos, também de natureza ética exigem que, ao adentrar no estudo, o participante seja perfeitamente esclarecido que poderá ser alocado em um grupo que será exposto a determinado fator ou em um grupo controle que receberá uma exposição fictícia denominada placebo, porém o resultado dessa alocação não poderá ser de seu conhecimento, devido à possibilidade de invalidar o resultado do estudo pela ação de fatores subjetivos ligados ao participante. Estudos deste tipo, nos quais o participante não sabe a que grupo pertence, são chamados estudos cego.

Por outro lado, fatores subjetivos ligados a quem observa o estudo e coleta os dados podem também influenciar a investigação e seus resultados. Para contornar essa possibilidade, omite-se, também do investigador, qual grupo recebe determinado tratamento, resultando no estudo denominado duplo-cego, onde nem o paciente nem o pesquisador sabem qual é a exposição sofrida por cada grupo. 
Recomenda-se ainda, que esse desconhecimento seja estendido, também, aos responsáveis pela análise dos dados e dos resultados do estudo, evitando uma possível influência subjetiva na escolha dos testes a serem empregados e na aplicação destes. Um estudo com essas características é chamado de triplo-cego.

Em alguns experimentos clínicos controlados, pode ser difícil realizar o estudo duplo-cego pela dificuldade de se ocultar o tipo de procedimento a que os grupos foram expostos. Este é o caso da avaliação econômica do impacto da atividade de ATENFAR, onde é difícil a criação de um placebo a ser aplicado no grupo controle para mimetizar este serviço e onde é necessário, por questões éticas, que o paciente seja informado e consinta em receber tal serviço. Desta forma, fica evidente aos participantes do grupo ao qual é oferecido serviço de ATENFAR que eles recebem um tratamento diferenciado, o que pode levar à inserção de fatores subjetivos ao estudo.

Durante o período de seguimento dos pacientes, os participantes de todos os grupos deverão ser acompanhados de forma semelhante, utilizando-se dos mesmos instrumentos e das mesmas condições para a coleta de dados. Quando o tempo de seguimento for muito curto, situação em que os resultados surgem em poucos meses, pode-se pensar que as perdas durante o acompanhamento serão pequenas, não comprometendo a análise dos resultados. Porém, se o tempo de seguimento for muito longo, até que surjam os resultados, pode-se esperar muitas perdas por desistências, mudanças de domicílio ou por outras causas.

Para lidar com situações desse tipo e com a entrada gradativa de participantes no estudo, é necessário fazer uso de um determinado artifício. O referido artifício é um denominador baseado no tempo de participação de cada um dos participantes no experimento, expresso por pessoa-tempo de seguimento. Para 
compor tal denominador calcula-se a densidade de incidência, somando a quantidade de tempo em que cada indivíduo foi exposto. O resultado será expresso por pessoa-tempo, sendo que uma pessoa-mês equivale a uma pessoa observada durante um mês, cem pessoas-mês equivale a cem pessoas observadas durante um mês ou dez pessoas observadas durante dez meses. Ou seja, cria-se um denominador artificial, que significa a contribuição do tempo de seguimento de cada participante (PEREIRA, 1995a).

O uso do conceito pessoa-tempo de exposição permite que todos os participantes que por algum momento fizeram parte do estudo sejam incluídos na análise, contornando assim o problema representado pelas perdas ocorridas ao longo da investigação e permitindo que pessoas sejam incluídas no estudo mesmo após o seu início, contando como tempo de exposição aquele em que elas permaneceram sob acompanhamento.

A comparação final dos resultados entre os grupos de estudo deverá ser realizada com cuidado e rigor, baseada em dados obtidos através de coleta pautada em critérios sensíveis e específicos.

Como mencionado anteriormente, a representação dos estudos analíticos apenas com dois grupos atende a finalidades puramente didáticas. Em um experimento destinado a avaliar o impacto da prestação de ATENFAR nos custos de tratamentos de saúde (grupo caso), é possível avaliar esse serviço em relação a opção de não prestá-lo adicionalmente ao tratamento (grupo controle) ou ainda, comparar a prestação de ATENFAR mediante outras opções de investimento, destinadas à mesma população, que tragam resultados comparáveis, através de algum tipo de análise econômica, aos resultados que possam ser propiciados pela ATENFAR. Tais alternativas de investimento podem ser um serviço de fisioterapia, 
um serviço de psicologia, um serviço de enfermagem, um serviço médico adicional, investimento em saneamento básico, um programa de distribuição de medicamentos, dentre outras.

De acordo com Silva e Formigli (1994), numa perspectiva metodológica quantitativa, como é caso das avaliações econômicas em saúde nas quais são comparadas relações de custo-resultado entre as alternativas concorrentes, o desenho epidemiológico "ideal" para a condução do estudo corresponde ao modelo experimental randomizado. Outros autores compartilham da mesma opinião de Silva e Formigli (1994), exaltando as vantagens da utilização do modelo experimental para a realização de avaliações econômicas em saúde (SIMON; WAGNER; VONKORFF, 1995; SHELDON, 1996; ELLWEIN; DRUMMOND, 1996; BUXTON et al., 1997; WALLEY; HAYCOX, 1997; HAYCOX; DRUMMOND; WALLEY, 1997; ODEGARD et al., 2005).

Alguns autores denominam de quase-experimentais os estudos desenvolvidos com grupos humanos ou animais onde uma ou mais variáveis fogem ao controle do pesquisador, mas que, apesar disso, não perdem sua validade como produtores de evidências científicas (ROTHMAN; GREENLAND, 1998).

Abaixo estão listadas, no quadro 4, algumas vantagens e limitações do método epidemiológico tipo experimental, segundo Pereira (1995a): 


\section{VANTAGENS}

- Alta credibilidade como produtor de evidências científicas;

- Os grupos (de estudo e controle) têm grande chance de serem comparáveis em termos de variáveis de confundimento se o tamanho da amostra for grande;

- Não há dificuldade na formação do grupo controle;

- O tratamento e os procedimentos são decididos a priori e uniformizados na sua aplicação;

- A qualidade dos dados sobre a intervenção e os efeitos pode ser de excelente nível, já que é possível proceder à sua coleta no momento em que os fatos ocorrem;

- A cronologia dos acontecimentos é determinada sem equívocos, pois existe certeza de que o tratamento é aplicado antes de aparecerem os efeitos;

- A intervenção e a verificação dos resultados podem ser dissimuladas, com o uso de placebos e técnicas de aferição duplo-cega, de modo a não influenciar examinados e examinadores;

- A interpretação dos resultados é simples, pois estão relativamente livres dos fatores de confundimento;

- Várias tecnologias sanitárias podem ser investigadas simultaneamente.

\section{LIMITAÇÕES}

- Aspectos éticos impedem que algumas situações sejam pesquisadas com esta metodologia;

- A necessidade de consentimento dos participantes (população estável e cooperativa) dificulta o desenvolvimento de pesquisas com esta metodologia, pois existe a possibilidade de haver recusas em participar e perdas de seguimento;

- O grupo investigado pode ser altamente selecionado, não-representativo, devido a múltiplas exigências quanto às características de inclusão e exclusão dos participantes no estudo;

- Alguns participantes podem deixar de receber um tratamento potencialmente benéfico, ou serem expostos a um procedimento potencialmente maléfico;

Quadro 4: Vantagens e limitações do método de estudo experimental.

Uma vez que motivos de natureza ética limitam o uso do modelo experimental com seres humanos, o estudo de associação entre possíveis fatores causais e determinados efeitos é realizado, muitas vezes, por meio de modelos não experimentais ou observacionais. Estes têm como principal característica o fato de que a alocação dos indivíduos nos grupos de estudo é realizada pelo acaso, por condições da própria história de vida ou condições de meio ambiente dos indivíduos, sem a interferência do pesquisador que simplesmente observa, de modo sistemático, a ocorrência ou não de determinado evento em uma realidade que não 
foi por ele manipulada. Assim sendo, eventuais diferenças nos resultados entre os grupos poderão ser devidas a diferenças em suas composições (viés de seleção) e não a diferentes exposições (HADDAD, 2004; PASSOS; RUFFINO-NETTO, 2005a).

Os estudos observacionais são divididos em transversais e longitudinais. O estudo transversal, como o próprio nome sugere, é um corte instantâneo que se faz em uma população, através de uma amostragem probabilística, examinando-se, simultaneamente, nos indivíduos da amostra, a presença ou ausência da exposição e a presença ou ausência do efeito. Neste estudo não se tem idéia, no tempo, sobre a antecedência da exposição em relação ao aparecimento do efeito. O investigador insere os participantes a partir da população ou de uma amostra dessa, sem que ele saiba, a priori, quais são os expostos, os não-expostos, os que apresentaram e os que não apresentaram o resultado esperado (HADDAD, 2004).

O quadro 5 mostra algumas vantagens e limitações desse método, segundo Pereira (1995a):

\section{VANTAGENS}

- Simplicidade e baixo custo;

- Rapidez, pois os dados sobre exposição, efeito e características das pessoas e do ambiente referem-se a um único momento e podem ser coletados em curto intervalo de tempo;

- Objetividade na coleta de dados;

- Não há necessidade de seguimento dos participantes;

- Facilidade para obter amostra representativa da população;

- Único tipo de estudo possível de realizar, em numerosas ocasiões, para obter informação relevante, em limitação de tempo e de recursos.

\section{LIMITAÇÕES}

- Possibilidade de erros de classificação, pois os casos podem não ser mais casos no momento da coleta de dados, o mesmo acontecendo com a exposição;

- Dados de exposição atual podem não representar a exposição passada;

- A relação cronológica entre os eventos pode não ser facilmente detectável, prejudicando, muitas vezes, a relação causa e efeito;

- Interpretação dificultada pela presença de variáveis de confundimento ou de variáveis não observáveis.

Quadro 5: Vantagens e limitações do método de estudo transversal. 
Ao contrário dos estudos transversais, nos estudos longitudinais, há uma seqüência conhecida, no tempo, entre a exposição e o aparecimento do efeito, isto é, sabe-se que houve, previamente, uma exposição e depois surgiu o efeito.

Os estudos longitudinais podem ser do tipo coorte ou do tipo caso-controle. No primeiro, o pesquisador cataloga grupos de indivíduos expostos e verifica, após um período latente de exposição, a presença ou ausência do efeito nesses grupos. Em epidemiologia coorte significa um grupo de indivíduos que têm uma característica comum que é a presença de uma exposição a um fator em estudo ou, então, a ausência da exposição a esse fator (PEREIRA, 1995a; PASSOS; RUFFINO-NETTO, 2005c).

A principal característica dos estudos de coorte é a seleção da população feita a partir da variável independente (exposição), aproveitando que diferentes grupamentos humanos naturalmente se expõem ou não à ação de um fator qualquer. Portanto, ao contrário do modelo experimental, o investigador não determina a exposição, mas usa grupos naturalmente expostos e não-expostos para neles medir o aparecimento de um resultado que, em sua hipótese, esteja associado à exposição (PEREIRA, 1995a; HADDAD, 2004 PASSOS; RUFFINO-NETTO, 2005c).

Conceitualmente, o modelo de coorte aproxima-se do modelo experimental, dele diferindo pelo fato da alocação dos indivíduos nos grupos caso e controle não ser definida pelo experimentador.

Os estudos tipo coorte possuem duas subdivisões que são o coorte prospectivo e o coorte retrospectivo. Se o investigador iniciar seu estudo antes do aparecimento do efeito, catalogando os indivíduos em expostos e não expostos, para depois segui-los no tempo para verificar se o efeito incide ou não, este modelo 
é chamado de coorte prospectivo. Se, entretanto, o investigador iniciar seu estudo quando tudo já aconteceu, isto é, já houve a exposição, já houve a passagem do tempo e já ocorreu a incidência do efeito e ele vai reconstruir, historicamente, as coortes de expostos e não-expostos e os que sofreram ou não o efeito, este estudo é chamado de coorte retrospectivo (HADDAD, 2004; PASSOS; RUFFINO-NETTO, 2005a).

No quadro 6 estão expostas algumas vantagens e limitações do método epidemiológico tipo coorte, segundo Pereira (1995a):

\section{VANTAGENS}

- Não há problemas éticos quanto a decisões de expor as pessoas a fatores de risco ou tratamentos, como acontece nos estudos experimentais;

- A seleção dos controles é relativamente simples;

- A qualidade dos dados entre exposição e efeitos pode ser de excelente nível, já que é possível proceder à sua coleta no momento em que os fatos ocorrem;

- Os dados referentes à exposição são conhecidos antes da ocorrência do efeito;

- A cronologia dos acontecimentos é facilmente determinada: primeiro ocorre a exposição e depois ocorre o desfecho;

- Muitas intervenções podem ser investigadas simultaneamente.

\section{LIMITAÇÕES}

- Falta de comparabilidade, em potencial, entre as características do grupo de expostos e de não-expostos, pois o investigador não aloca, aleatoriamente, os participantes em tais grupos;

- Alto custo, principalmente nos estudos prospectivos de longa duração;

- Perdas de seguimento podem ser grandes;

- Dificuldade de implementar testes cegos;

- Interpretação dificultada pela presença de variáveis de confundimento ou de variáveis não observáveis.

- Grande dificuldade para realizar estudos retrospectivos, pois dados históricos podem ser perdidos com grande facilidade.

Quadro 6: Vantagens e limitações do método de estudo tipo coorte.

No estudo tipo caso-controle, também já ocorreu a exposição e o efeito, porém, diferentemente do estudo de coorte, tipo retrospectivo, a catalogação dos indivíduos não é feita a partir da exposição (presente ou ausente), como neste último, mas sim a partir do efeito (presente ou ausente) e vai verificar, em ambos, a 
presença ou ausência de exposição prévia ao fator em estudo. Assim, os indivíduos que sofreram o efeito são chamados de casos e os que não sofreram o efeito são chamados de controles. Tanto para os casos, como para os controles, será investigada a exposição prévia ao fator em estudo de modo a testar a hipótese de que tais fatores de risco são causas contribuintes do efeito (HADDAD, 2004).

No quadro 7 estão listadas algumas vantagens e limitações do método epidemiológico tipo caso-controle, segundo Pereira (1995a):

\begin{tabular}{|ll|}
\hline \multicolumn{2}{|c|}{ VANTAGENS } \\
\hline - & Os resultados são obtidos rapidamente; \\
\hline - & Baixo custo; \\
\hline - & Muitas intervenções podem ser investigadas simultaneamente; \\
\hline - & Não há necessidade de acompanhamento dos participantes; \\
\hline & \multicolumn{1}{c|}{ LIMITAÇÕES } \\
\hline - & A seleção do grupo controle é uma grande dificuldade; \\
\hline - & Falta de comparabilidade entre as características de casos e controles; \\
\hline & Osontuários de exposição no passado podem quando baseados na memória das pessoas; \\
\hline - & Os dados de exposição podem ser viciados: o grupo caso tem melhor noção de \\
& possíveis exposições do que o grupo controle; \\
\hline - & Interpretação dificultada pela presença de variáveis de confundimento ou de \\
& variáveis não observáveis. \\
\hline
\end{tabular}

Quadro 7: Vantagens e limitações do método de estudo tipo caso-controle.

Em uma avaliação econômica em saúde, devido à necessidade de se computar todos os custos relacionados a uma tecnologia sanitária para que os resultados da análise econômica sejam metodologicamente plausíveis, é necessário que os custos dos tratamentos, das ações, dos serviços de saúde, sejam monitorados e computados desde o início da atividade, ou seja, desde a exposição do paciente ao fator, visando contabilizar o custo total da mesma. Desta forma, os métodos epidemiológicos mais indicados para serem utilizados em estudos desta natureza são os prospectivos (experimental e coorte prospectivo), pois se forem 
utilizados métodos retrospectivos, os pacientes terão que recordar custos e resultados que vivenciaram no passado e o pesquisador terá que rastrear todos os custos e resultados incorridos, acarretando possivelmente em vieses.

Alguns autores, ao trabalharem conceitos e ferramentas da avaliação econômica do uso de medicamentos e de intervenções farmacêuticas, optaram por chamar esse campo de estudo de farmacoeconomia.

De acordo com Zanini et al. 2001, embora empregando a palavra "fármaco" em sua nomenclatura, a farmacoeconomia apresenta ferramentas que podem ser utilizadas igualmente na avaliação de medicamentos, programas de saúde e mesmo de sistemas administrativos, desde que observadas as devidas características de cada um.

Segundo Mota; Fernandes e Coelho (2003), a farmacoeconomia não deve se restringir unicamente à avaliação econômica de medicamentos, mas também, à avaliação econômica de intervenções e serviços farmacêuticos.

Segú (2002) apud Mota; Fernandes e Coelho (2003) ${ }^{5}$, afirma que as avaliações econômicas podem ser aplicadas nos seguintes âmbitos da assistência farmacêutica:

- Análise organizativa dos serviços farmacêuticos;

- Priorização de atividades e intervenções na gestão clínica do medicamento;

- Análise de custos e produtividade dos serviços de Atenção Farmacêutica;

- Análise de custos derivados dos problemas relacionados aos medicamentos;

- Avaliação econômica de intervenções de Atenção Farmacêutica;

- Avaliação econômica de medicamentos nos processos de seleção.

\footnotetext{
${ }^{5}$ SEGÚ, J. L.. Utilidades de la Farmacoeconomía en la Gestión de Medicamentos en el Ámbito de los Proveedores de Servicios de Salud. Curso Avanzado en Farmacoeconomía (on-line) <www.pnu.es>
} 
Segundo a International Society for Pharmacoeconomics and Outcomes Research (ISPOR), farmacoeconomia é o "campo de estudo que avalia o comportamento de indivíduos, empresas e mercados com relação ao uso de produtos, serviços e programas farmacêuticos, e que, freqüentemente, enfoca os custos e conseqüências desta utilização" (PASHOS; KLEIN; WANKE, 1998).

Para viabilizar a realização de qualquer tipo de estudo de avaliação econômica no setor saúde, o ponto de partida deve ser a introdução de sistemas de custeio nas organizações. Esses sistemas organizam as informações existentes e constroem outras fundamentais para a realização de avaliações econômicas dos serviços sanitários (CASTRO, 2002).

Entende-se por sistemas de custeio os processos destinados à alocação de custos a um determinado produto ou serviço, sendo os mais utilizados, tradicionalmente, inclusive em saúde, o custeio integral ou custeio por absorção e o custeio direto ou custeio marginal.

Recentemente, um outro sistema de custeio, denominado custeio baseado em atividades ou sistema $A B C$ (da denominação original no idioma inglês - activity based costs), passou a ser utilizado na área da saúde e aparece no cenário contábil/econômico como o método mais "robusto" para alocar, fidedignamente, aos produtos e serviços, seus reais custos.

O sistema de custeio por absorção ou tradicional é o mais utilizado nas instituições públicas brasileiras. Ele apropria todos os custos incorridos para a produção de um bem ou serviço, ou seja, considera os custos diretos, indiretos, fixos e variáveis (CASTRO, 2002; SANTANA, 2003). 
A primeira condição para a utilização deste sistema de custeio é a setorização ou divisão da instituição em centros de custos. A partir do plano de centros de custos é que se procede aos rateios dos custos fixos indiretos para serem apropriados ao custo final o produto (CRC-SP 1995, BEULKE; BERTÓ, 1997). Por rateio, entende-se a divisão proporcional de um custo indireto ou despesa geral de produção entre os diversos setores de uma instituição.

A principal desvantagem do sistema de custeio por absorção é a dificuldade de realização dos rateios dos custos indiretos, que são feitos utilizando-se critérios arbitrários, o que implica, muitas vezes, avaliação incorreta dos custos finais (CASTRO 2002; CASTRO 2003).

O sistema de custeio direto ou marginal considera apenas os custos diretos gastos para produzir produtos ou serviços. Todos os custos que não estejam diretamente relacionados com o produto ou o serviço não são apropriados ao seu custo final. Neste sistema, não são considerados os custos dos setores de apoio ou administrativos, o que acarreta na inconsistência dos dados de custos, não refletindo a realidade (BEULKE; BERTÓ, 1997).

O sistema de custeio por atividades, por sua vez, é um sistema de custos que tem o objetivo de avaliar com precisão as atividades desenvolvidas em uma empresa (industrial ou de prestação de serviços), utilizando direcionadores de custo para alocar as despesas indiretas de uma forma mais realista aos produtos e serviços. O ABC parte do princípio de que não é o produto ou serviço que consome recursos, mas sim, as atividades e estas, por sua vez, são consumidas pelo produto ou serviço (NAKAGAWA, 1994; MARTINS, 2002).

Considerado muitas vezes um sistema de difícil implantação, trata-se, em sua essência, de uma poderosa metodologia de custeamento que procura reduzir 
sensivelmente as distorções provocadas pelos sistemas tradicionais, os quais atribuem custos fixos indiretos aos produtos de acordo com bases de rateio arbitrárias.

Caso haja necessidade, uma organização pode utilizar, simultaneamente, mais de um sistema de apropriação de custos, visto que esses não são excludentes entre si, cada qual podendo ser utilizado em determinado setor para a obtenção de informações específicas (CASTRO, 2002; SANTANA, 2003).

Os custos implicam o valor de todos os recursos utilizados na produção de bens e serviços, sendo que os mesmos podem ser classificados de diversas formas, segundo os autores lunes (1995); Garber et al. (1996); Villar (2000); Horngren; Forster; Datar (2000); Abbas (2001) e Tanaka e Melo (2004):

- Custos Tangíveis: são os custos que têm um valor monetário agregado e, por isso, são passíveis de serem quantificados (ex.: número de atendimentos realizados, quilos de roupa lavada, número de exames realizados, quantidade de medicamentos consumidos);

- Custos Intangíveis: são os custos que carecem de um valor monetário ou de um significado econômico. Sua valorização é subjetiva (variabilidade interpessoal) e está relacionada ao ônus psicológico gerado, e, por isso, são de difícil quantificação (ex.: dor, sofrimento, incapacidade na execução de determinadas atividades, perda de qualidade de vida);

- Custos Fixos: são os custos que não variam em função da quantidade de produtos ou serviços gerados ou consumidos (ex.: aluguel, equipamentos);

- Custos Variáveis: são os custos que estão diretamente relacionados à quantidade de produtos ou serviços gerados ou consumidos. Variam de acordo com 
o rendimento dos processos (ex:: medicamentos, filmes radiográficos, materiais médico-hospitalares);

- Custos Mistos: apresentam características de custo fixo até certo nível de produtividade e, quando se atinge tal nível, é necessário que haja um incremento dos recursos disponíveis, passando, pontualmente, a variável, voltando a reassumir sua característica de custo fixo logo em seguida (ex.: mão-de-obra);

- Custos Diretos: são os custos de insumos relacionados diretamente com a concepção ou execução de um serviço ou produto (ex.: exames realizados, medicamentos, salários da equipe de saúde, materiais médico-hospitalares, diárias de internação, dieta especial);

- Custos Indiretos: são custos que não se relacionam de forma imediata com a concepção ou execução de um produto ou serviço. Também são denominados custos indiretos os custos representados por ganhos não realizados, fatos sempre presentes na maioria das situações de doença e que envolvem o próprio paciente e seus cuidadores (ex.: energia elétrica, lavanderia, processos administrativos, perda de produtividade em virtude de seqüelas, perda temporária ou definitiva da capacidade de trabalho, morte prematura, necessidade de cuidadores, ausência no trabalho);

- Custo Total: corresponde ao valor total gasto, num determinado período, para produzir certa quantidade de bens ou serviços (ex.: preparo de bolsas de nutrição parenteral em um determinado mês);

- Custo Médio ou Unitário: corresponde ao valor total gasto para produzir bens ou serviços num determinado período, dividido pelo número de unidades desses bens ou serviços produzidos (ex.: uma bolsa de nutrição parenteral); 
- Custo de Depreciação: decréscimo do valor monetário de um bem devido à passagem do tempo, uso, obsolescência. Geralmente, é aplicado a bens duráveis e seu valor é definido pelo mercado que comercializa tal bem (ex.: valor de uma máquina, de um imóvel ou de um automóvel após uma década, frente ao seu preço inicial);

- Custo de Oportunidade: é o valor dos benefícios da melhor alternativa que se possa escolher. Está relacionado ao sentimento de deixar de ganhar por escolher uma alternativa em detrimento de outra. Só pode ser aplicado nos casos em que os recursos disponíveis para atender às necessidades são limitados, de modo que não é possível satisfazer a todas (ex.: possíveis benefícios gerados pelo tratamento de um hipertenso quando se opta por destinar a verba sanitária para a realização de uma cirurgia plástica).

Devido aos múltiplos fatores, relatados acima, envolvidos na execução de uma análise econômica em saúde, Drummond et al. (1997) desenvolveram e sugeriram uma lista de checagem para a apreciação da qualidade dessas avaliações, caracterizada pela adoção dos seguintes critérios:

- Os objetivos da análise econômica foram adequadamente esclarecidos?

- Foi oferecida uma descrição abrangente das alternativas concorrentes?

- Foi estabelecida a efetividade do programa ou serviço?

- Foram identificados todos os custos e conseqüências importantes e relevantes de cada alternativa?

- Custos e conseqüências foram mensurados adequadamente e em unidades apropriadas?

- Foram avaliados custos e conseqüências com credibilidade?

- Custos e conseqüências foram ajustados para diferentes períodos de tempo? 
- Foi realizada uma análise incremental (adicional)?

- Foi realizada uma análise de sensibilidade?

- A apresentação e a discussão dos resultados do estudo incluíram todos os assuntos concernentes aos usuários?

No Brasil, a realização de avaliações econômicas completas nos serviços de saúde, contemplando todos os requisitos formulados por Drummond et al. (1997), é incipiente. Até o que foi chamado de "descrição de custos" e "descrição de resultados" é praticamente inexistente (CASTRO, 2002). Quando se trata de serviços públicos, a literatura científica a respeito de análises econômicas é ainda mais restrita (FERREIRA; LOUREIRO, 2006).

Este cenário também é observado nas avaliações econômicas do impacto da atividade de ATENFAR, que, apesar de suas peculiaridades, deve, em linhas gerais, seguir as recomendações preconizadas e consagradas para a realização de avaliações de outros tipos de serviços sanitários (tipo de análise econômica a ser utilizada, modelo de estudo epidemiológico, perspectivas de análise, formas de apuração e de equiparação de custos e resultados).

Acatar que a saúde não é um bem absoluto justifica o emprego da avaliação econômica para a tomada de decisões. A avaliação econômica nem sempre oferece respostas simples e indiscutíveis, porém reforça a explicação de informações e as suposições e conceitos de valores que requerem um raciocínio lógico (CEARÁ, 2001). 


\section{CONCLUSÕES}

- As análises econômicas tipo custo-minimização, tipo custo-efetividade, tipo custo-utilidade e tipo custo-benefício, são aplicáveis a avaliações econômicas do impacto da ATENFAR, salvaguardadas as peculiaridades de cada tipo de análise.

- Os custos relativos aos salários dos farmacêuticos, dos auxiliares e dos demais membros da equipe de saúde; ao transporte do paciente ou da equipe de saúde; aos materiais de consumo; aos medicamentos; às internações hospitalares; aos atendimentos médicos de urgência; às sensações de dor, de tristeza, de mal estar; aos dias de trabalho perdidos, à necessidade de um cuidador; ao aluguel, à conta de energia e à administração do espaço destinado ao serviço de ATENFAR; são custos a serem levantados em uma avaliação econômica do impacto desses serviços;

- A melhoria em parâmetros clínicos (redução da pressão arterial, controle do nível glicêmico), a melhoria da qualidade de vida dos pacientes atendidos pelo serviço de ATENFAR e a economia de recursos financeiros (internações, atendimentos de urgência e tratamentos sanitários adicionais evitados), são possíveis resultados gerados por serviços de ATENFAR, todos decorrentes da prevenção ou do tratamento de PRM.

- As análises econômicas do impacto da atividade de ATENFAR podem ser realizadas sob a perspectiva (ponto de vista), do paciente, da instituição de saúde, do plano de saúde, do sistema de saúde, da sociedade ou de qualquer outro agente que tenha interesse em apurar o impacto econômico da ATENFAR frente a alternativas de assistência à saúde e/ou de investimento, considerando 
as particularidades de cada ponto de vista, em especial a concepção de custos e resultados.

- Os modelos de estudos epidemiológicos mais indicados para serem utilizados em análises econômicas do impacto da atividade de ATENFAR são o modelo experimental, prioritariamente, e o modelo observacional longitudinal tipo coorte prospectivo, caso não haja a possibilidade de se implementar um estudo experimental. 


\section{REFERÊNCIAS BIBLIOGRÁFICAS ${ }^{6}$}

ABBAS, K.. Gestão de custos em organizações hospitalares. 2001. 155 f. Dissertação (Mestrado em Engenharia de Produção), Universidade Federal de Santa Catarina, Florianópolis, 2001.

AGRO, K. E.; BRADLEY, C. A.; MITTMANN, N.; ISKODJIIAN, M.; ILERSICH, A. L.; EINERSON, T. R.. Sensitivity analysis in health economic and pharmacoeconomic studies. Pharmacoeconomics, v. 11, p. 75-88. 1997.

AJAYI, F. O.; SUN, H.; PERRY, J.. Adverse drug reactions: a review of relevant factors. Journal of Clinical Pharmacology, v. 40, p. 1093-1101. 2000.

ANDERSON, L.; GANGS, J.. Jornadas sobre managed care y pharmaceutical care. Boletín Fepafar, v. 11, p. 11-15, 1997.

ARANCÍBIA, A.; CID, E.; DOMECQUE, C.; PAULOS, C.; PEZZANI, M.; PINILLA, E.; ROJAS, M.; RUIZ, I.; VARGAS, M.. Fundamentos de Farmacia Clínica. Santiago, Chile: Piade/Universidad de Chile; 1993. 372 p..

ARAÚJO, R. C.. O papel do farmacêutico na prevenção de problemas relacionados ao uso de medicamentos: resultados do projeto Fleetwood. Farmacoterapêutica, n. 7, p. 63-66, mar./abr. 2001.

AMERICAN SOCIETY OF HOSPITAL PHARMACISTS (ASHP). ASHP statement on pharmaceutical care. American Journal of Hospital Pharmacy, v. 50, p. 17201723. 1993.

ATALLAH, A. N.. Medicina baseada em evidências: o elo entre a boa ciência e a boa prática clínica. In: FRANCO, L. J.; PASSOS, A. D. C. (orgs). Fundamentos de epidemiologia. Barueri: Manole; 2005. Cap. 21, p. 355-372.

BASSKIN, L. E.. Practical pharmacoeconomics: how to design, perform and analyze outcomes research. Cleveland, EUA: Advanstar; 1998. 173p..

BATES, D.. Incidence of adverse events and potential adverse drug events. Journal of American Medical Association, v. 274, p. 29-34. 1995.

BENSON, S.; VANCE-BRYAN, K.; RADDATZ, J.. Time to patient discontinuation of antihypertensive drugs in different classes. American Journal of Health-System Pharmacy, v.57, p.51-54, Jan. 2000.

\footnotetext{
${ }^{6}$ De acordo com a NBR 6023, preconizada pela Associação Brasileira de Normas Técnicas (ABNT), apresentada nas Diretrizes para apresentação de dissertações e teses da USP. São Paulo, 2004.
} 
BERGER, B. A.. Communication skills for pharmacists: building relationships, improving patient care. Washington DC, EUA: American Pharmaceutical Association; 2002. 166 p..

BERNSTEN, C.; BJORKMAN, I.; CARAMONA, M.; CREALEY, G.; FROKJAER, B.; GRUNDBERGER, E.; GUSTAFSSON, T.; HENMAN, M.; HERBORG, H.; HUGUES, C.; McELNAY, J.; MAGNER, M.; VAN MIL, F.; SCHAEFFER, M.; SILVA, S.; SONDERGAARD, B.; STURGESS, I.; TROMP, D.; VIVERO, L.; WINTERSTEIN, A.. Improving the well-being of elderly patients via community pharmacy-based provision of pharmaceutical care: a multicentre study in seven European countries. Drugs \& Aging, v. 18, n. 1, p. 63-77, Jan. 2001.

BEULKE, R.; BERTÓ, D. J.. Gestão de custos e resultados na saúde: hospitais, clínicas, laboratórios e congêneres. São Paulo: Saraiva; 1997. 192 p..

BEVILÁQUA, L. D. P. Farmacoeconomia. In: GOMES, M. J. V. M.; REIS, A. M. M. (orgs). Ciências farmacêuticas: uma abordagem em farmácia hospitalar. São Paulo: Atheneu; 2001. Cap. 11, p. 191-220.

BILLUPS, S. J.; MALONE, D. C.; CARTER, B. L.. Relationship between drug therapy noncompliance and patient characteristics, health-related quality of life, and health care costs. Pharmacotherapy, v. 20, n. 8, p. 941-999, Ago. 2000.

BISSON, M. P.. Farmácia clínica \& atenção farmacêutica. São Paulo: Medfarma; 2003. 356 p..

BLUML, B. M.; MC KENNEY; CZIRAKY, M. J.. Pharmaceutical care services and results in project ImPACT: hyperlipidemia. Journal of American Pharmaceutical Association, v. 40, n. 2, p. 157-165, Mar./Apr. 2000.

BOOTMAN, J. L.; TOWSEND, R. J.; MC GHAN, W. F.. Principles of pharmacoeconomics. 2. ed. Cincinnati, EUA: Harvey Books Company; 1996. 302 p..

BORDET, R.; GAUTIER, S.; LE LOUET, H.; DUPUIS, B.; CARON, J.. Analysis of the direct cost of adverse drug reactions in hospitalized patients. European Journal of Clinical Pharmacology, v. 56, p. 935-941. 2001.

BOWLING, A. Evaluating health services: multidisciplinary collaboration. In: BOWLING, A. Research methods in health. Buckingham, EUA. Open University Press; 1997. Cap. 1, p. 6-16.

BROUWER, W.; KOOPMANSCHAP, M.. "On the economic foundations of CEA: ladies and gentlemen, take your positions!". Journal of Health Economics, v. 19, p. 439-459. 2000. 
BUXTON, M. J.; DRUMMOND, M. F.; VAN HOUT, B. A.; PRINCE, R. L.; SHELDON, T. A.; SZUCS, T.; VRAY, M.. Modeling in economic evaluation: an unavoidable fact of life. Health Economics, v. 6, n. 3, p. 217-227. May./Jun.1997.

CAIRNS, J.. Discounting in economic evaluation. In: DRUMMOND, M. F.; MC GUIRE, A. (eds). Economic evaluation in health care: merging theory with practice. Nova York, EUA: Oxford University Press; 2001. Cap. 10, p. 236-255.

CAMPELL, S. M.; ROLAND, M. O.; BUETOW, S. A.. Defining quality of care. Social Science \& Medicine, v. 51, n. 11, p. 1611-1625. 2000.

CASTRO, J. D.; ROCHA, V.; MARINHO, M.; PINTO, S.. O custo efetividade: uma comparação entre o modelo "tradicional" e o modelo do programa de saúde da família. $2003 \quad$ Disponível em: <http://www.abres.cict.fiocruz.br/trabalhos/mesa1/3.pdf> Acesso em: 16/07/2006.

CASTRO, J.D. Instrumentos para avaliação econômica dos serviços de saúde. $2002 . \quad$ Disponível em: $<$ http://www.ipea.gov.br/economiadasaude/subtema.php?cod=16\#> Acesso em: 24/11/2005.

CAVALLO, F.; TRAVERSA, G.; PIERGENTELI, P.; RENGA, G.. Qualità ed efficacia dei servizi sanitari: un sistema di indicatori per la programmazione regionale. Milão: Cresa; 1988. 192 p..

CEARÁ. Secretaria Estadual da Saúde. Farmacoeconomia: guia breve. Fortaleza: SESA; 2001. 56 p..

CERULLI, J.. The role of the community pharmacist in identifying, preventing and resolving drug-related problems. Medscape Pharmacists, v. 2, n. 2, p. 1-5, Feb. 2001.

CICONELLI, R. M.. Tradução para o português e validação do questionário genérico de avaliação da qualidade de vida "Medical Outcomes Study 36-Item Short-Form Health Survey (SF-36 ${ }^{\circledR}$ )". 1997. 170 f. Tese (Doutorado). Escola Paulista de Medicina, Universidade Federal de São Paulo, São Paulo, 1997.

CIPOLLE, R. J.; STRAND, L. M.; MORLEY, P. C.. El ejercicio de la atención farmacéutica. Madri, Espanha: McGraw Hill/ Interamericana; 2002. 352 p..

CLASSEN, D. C.; PESTOTNIK, S. L.; EVANS, R. S.; LLOYD, J. F.; BURKE, J. P.. Adverse drug events in hospitalized patients: excess length of stay, extra costs, and attributable mortality. Journal of American Medical Association, v. 277, n. 4, p. 301-306, Jan. 1997.

COHEN, E.; FRANCO, R.. Avaliação de projetos sociais. Petrópolis: Vozes; 1998. 312 p.. 
CONTANDRIOPOULOS, A. P.; CHAMPAGNE, F.; PINEAULT; R.. Avaliação na área da saúde: conceitos e métodos. In: HARTZ, Z. M. A. (org). Avaliação em saúde: dos modelos conceituais à prática na análise da implantação de programas. Rio de Janeiro: Fiocruz; 1997. Cap. 2, p. 29-48.

COUTTOLENC, B. F.. Por que Avaliação econômica em saúde?. Revista da Associação Médica Brasileira, v. 47, n. 1. p. 18-19. 2001.

COUTTOLENC, B. F.; ZUCCHI. P.. Gestão de recursos financeiros. São Paulo: Faculdade de Saúde Pública-USP; 2002. 124 p. (série Saúde e Cidadania).

COWPER, P. A.; WEINBERGER, M.; HANLON, J. T.; LANDSMAN, P. B.; SAMSA, G. P.; UTTECH, K. M.; SCHMADER, K. E.; LEWIS, I. K.; COHEN, H. J.; FEUSSNER, J. R.. The cost-effectiveness of a clinical pharmacist intervention among elderly outpatients. Pharmacotherapy, v. 18, p. 327-332. 1998.

CONSELHO REGIONAL DE CONTABILIDADE DE SÃO PAULO (CRC-SP). Custo como ferramenta gerencial. São Paulo: Atlas. 1995. 178p..

DAL FABBRO, A. L.. Causalidade em epidemiologia. In: FRANCO, L. J.; PASSOS, A. D. C. (orgs.). Fundamentos de epidemiologia. Barueri: Manole; 2005. Cap. 17, p. 287-298.

DANTAS, R. A. S.; SAWADA, N. O.; MALERBO, M. B.. Pesquisas sobre qualidade de vida: revisão da produção científica das universidades públicas do estado de São Paulo. Revista Latino-Americana de Enfermagem, v. 11, n. 4, p. 532-538, jul./ago. 2003.

DEL CASTILHO, J. A. S.. Farmacoeconomia y evaluación económica de medicamentos: introducción. In: DEL CASTILHO, J. A. S.; LLACH, X. B.; ROVIRA, J. (orgs). Farmacoeconomia: evaluación económica de los medicamentos. Madri, Espanha: Médica; 1995. p. 19-29.

DEL NERO, C. R.. O que é economia da saúde. In: Piola, S. F.; Vianna, S. M. (orgs). Economia da saúde: conceito e contribuição para a gestão da saúde. 3. ed. Brasília: IPEA; 1995. Cap. I, p. 5-21.

DESLANDES, S. F.. Concepções em pesquisa social: articulações com o campo da avaliação em serviços de saúde. Cadernos de Saúde Pública, v. 13, n. 1, p. 103107, jan./mar. 1997.

DONABEDIAN, A.. The quality of care: how can it be assessed?. Journal of American Medical Association, v. 260, n. 12, p. 1743-1748. 1988.

DRUMMOND, M. F.. Como avaliar uma política de saúde. Tradução: Maria José Lindgren Alves. Caderno de ciência e tecnologia: avaliação tecnológica em saúde. Centro Brasileiro de Estudos de Saúde (CEBES). n. 1, p. 26-41, fev. 1991. 
DRUMMOND, M. F.. Economic evaluation and the rational diffusion and use of health technology. Health Policy, v. 7, p. 309-324. 1987.

DRUMMOND, M. F.; O'BRIEN, B. J.; STODDART, G. L.; TORRANCE, G. W. Methods for the economic evaluation of health care programmes. 2. ed. Londres, Inglaterra: Oxford University Press; 1997. 305 p.

DUPIM, J. A. A.. Assistência farmacêutica: um modelo de organização. Belo Horizonte: Segrac; 1999. 79 p..

DURÁN, I.; ROMERO, F. M.; FAUS, M. J.. Problemas relacionados con medicamentos resueltos en una farmacia comunitaria. Pharmaceutical Care España, v. 1, p. 11-19, jan. 1999.

EINARSON, T. R.. Drug-related hospital admission. Annals of Pharmacotherapy, v. 27, p. 832-840. 1993.

ELLIS, S. L.; BILLUPS, S. J.; MALONE, D. C.; CARTER, B. L.; COVEY, D.; MASON, B.; JUE, S.; CARMICHAEL, J.; GUTHRIE, K.; SINTEK, C. D.; DOMBROWSKI, R.; GERAETS, D. R.; AMATO, M.. Types of interventions made by clinical pharmacists in the IMPROVE study: impact of managed pharmaceutical care on resource utilization and outcomes in veterans affairs medical centers. Pharmacotherapy, v. 20, n. 4, p. 429-435, Apr. 2000.

ELLWEIN, L. B.; DRUMMOND, M. F.. Economic analysis alongside clinical trials: bias in the assessment of economic outcomes. International Journal of Technology Assessment Health Care, v. 12, p. 691-697. 1996.

ERWIN, W. G.. The role of consultant pharmacist. The Consultant Pharmacist, v. 14, n. 12, p. 1342-1351, Dec. 1999.

FAUS, M. J.. El programa Dáder. Pharmaceutical Care España, v. 2, p. 73-74, mar./abr. 2000.

FERRAZ, M. B.. Como aproveitar os recursos disponíveis. Revista do CREMESP, v. 17, n. 105, p. 8. 1996.

FERREIRA, C. A.; LOUREIRO, C. A.. Economia em saúde com foco em saúde bucal: revisão de literatura. Revista Epidemiologia e Serviços de Saúde, v. 15, n. 4, p. 55-65, out./dez. 2006.

FLECK, M. P. A.. Aplicação da versão em português do instrumento abreviado de avaliação da qualidade de vida "WHOQOL-bref". Revista de Saúde Pública, v. 34, n. 2, p. 350-306, abr. 2000.

FRIAS-BULHOSA, J.. Princípios e formas de avaliação econômica aplicadas à medicina dentária. Revista Portuguesa de Estomatologia, Medicina Dentária e Cirurgia Maxilofacial, v. 45, n. 2, p. 105-118. 2004. 
GARBER, A. M.; WEINSTEIN, M. C.; TORRANCE, G. W.; KAMLET, M. S.. Theoretical foundations of cost-effectiveness analysis. In: GOLD, M. R.; SIEGEL, J. E.; RUSSEL, L. B.; WEINSTEIN, M. C. (eds). Cost-effectiveness in health and medicine. Nova York, EUA: Oxford University Press; 1996. Cap. 2, p. 25-53.

GARÇÃO, J. A.; CABRITA, J.. Evaluation of a pharmaceutical care program for hypertensive patients in rural Portugal. Journal of American Pharmaceutical Association, v. 42, n. 6, p. 858-864, Nov./Dec. 2002.

GARIEPY, I. Asesoramiento farmacéutico en Canadá: una opinión que se paga. Boletín Fepafar, v. 10, p. 6-7. 1997.

GENUA, M. I.; MIRÓ, B.. Atención Farmacéutica en residencias de ancianos. Revista OFIL, v. 6, n. 1, p. 3-8. 1996.

GIL, A. C.. Métodos e técnicas de pesquisa social. 4. ed. São Paulo: Atlas; 1996. 208 p..

GONZÁLEZ, A. M. G.. La farmacoeconomia en la eficiencia de la salud pública. Revista Cubana de Salud Pública, v. 25, n. 1, p. 81-85. 1999.

GOURLEY, D. R.; GOURLEY, G. A.; SOLOMON, D. K.; PORTNER, T. S.; BASS, G. E.; HOLT, J. M.; BRADEN, R. L.; RAWLS, N.; WICKE, W. R.; OGDEN, J.; LAWRENCE, B.. Development, implementation, and evaluation of a multicenter pharmaceutical care outcomes study. Journal of American Pharmaceutical Association, v. 38, n. 5, p. 567-573. Sep./Oct. 1998.

GRAINGER-ROUSSEAU, T. J., MIRALLES, M. A., HEPLER, C. D., SEGAL, R., DOTY, R. E., BEN-JOSEPH, R. Therapeutic outcomes monitoring: application of pharmaceutical care guidelines to community pharmacy. Journal of American Pharmaceutical Association, v. 37, n. 6, p. 647-661. 1997.

HADDAD, N.. Metodologia de estudos em ciências da saúde: como planejar, analisar e apresentar um trabalho científico. São Paulo: Roca; 2004. 287p..

HARTZ, Z. M. A.; POUVOURVILlE, G.. Avaliação dos programas de saúde: a eficiência em questão. Ciência e Saúde Coletiva, v. 3, n. 2, p. 68-82. 1998.

HAYCOX, A.; DRUMMOND, A.; WALLEY, T.. PharmacoEconomics: integrating economic evaluation into clinical trials. Bristol Journal of Clinical Pharmacology, v. 43, p. 559-562. 1997.

HENNESSY, S.. Potentially remediable features of the medication: use environment in the United States. American Journal of Health System Pharmacy, v. 57, p. 543547. 2000. 
HEPLER, C. D.. The third wave in the pharmaceutical education: the clinical movement. American Journal of Pharmaceutical Education, v. 51, p. 369-385. 1987.

HEPLER, C. D.. Observations on the conference: a pharmacist's perspective. American Journal of Health System Pharmacy, v. 57, p. 590-594. 2000.

HEPLER, C.D; STRAND, L. M.. Opportunities and responsibilities in pharmaceutical care. American Journal of Hospital Pharmacy, v. 47, p. 533-543, Mar. 1990.

HERBORG, H.; SOENDERGAARD, B.; FROEKJAER, B.; FONNESBAEK, L.; JORGENSEN, T.; HEPLER, C. D.; GRAINGER-ROUSSEAU, T. J.; ERSBOELL, B. $\mathrm{K}$.. Improving drug therapy for patients with asthma - part 1: patient outcomes. Journal of American Pharmaceutical Association, v. 41, n. 4, p. 539-550, Jul./Aug. 2001a.

HERBORG, H.; SOENDERGAARD, B.; JORGENSEN, T.; FONNESBAEK, L.; HEPLER, C. D.; HOLST, H.; FROEKJAER, B.. Improving drug therapy for patients with asthma - part 2: use of antiasthma medications. Journal of American Pharmaceutical Association, v. 41, n. 4, p. 551-559, Jul./Aug. 2001b.

HERRERA, M. C.; DIÁZ, N. F.. Farmacoeconomia: evaluación de la eficiencia en los tratamientos farmacológicos. Revista Cubana de Farmacia, v. 34, n. 1, p. 63-69. 2000.

HERRERA-CARRANZA, J.. Objetivos de la atención farmacéutica. Atención Primaria, v. 30, n. 3, p. 183-187. 2002.

HODGSON, T. A.; CAI, L.. Medical expenditures for hypertension: its complications, and its comorbidities. Medical Care, v. 39, n. 6, p. 599-615. 2001.

HOLAND, R. W.; NIMMO, C. M.. Transitions, part 1: beyond pharmaceutical care. American Journal of Hospital Pharmacy, v. 56, p. 1758-1764, Sep. 1999.

HORNGREN, C. T.; FOSTER, G.; DATAR, S. M.. Contabilidade de custos. 9. ed. Rio de Janeiro: LTC - Livros Técnicos e Científicos; 2000. 701 p..

IGLESIAS, C. P.; DRUMMOND, M. F.; ROVIRA, J.; NEVALAT PROJECT GROUP. Health-care decision-making processes in Latin America: problems and prospects for the use of economic evaluation. International Journal of Technology Assessment Health Care, v. 21, n. 1, p.1-14. 2005.

IUNES, R.F.. A concepção econômica de custos. In: Piola, S. F.; Vianna, S. M. (orgs). Economia da saúde: conceito e contribuição para a gestão da saúde. 3. ed. Brasília: IPEA; 1995. Cap. X, p. 227-247. 
JABER, L.A.; HALAPY, H.; FERNET, M.; TUMMALAPALLI, S.; DIWAKARAN, H.. Evaluation of a pharmaceutical care model on diabetes management. Annals of Pharmacotherapy, v. 30, p. 238-243. 1996.

JOLICOEUR, L. M.; JONES-GRIZZLE, A. J.; BOYER, J. G.. Guidelines for performing a pharmacoeconomic analysis. American Journal of Hospital Pharmacy, v. 49, p. 1741-1747, Jul. 1992.

KENKEL, D.. On valuing morbidity, cost-effectiveness analysis, and being rude. Journal of Health Economics, v. 16, p. 749-757. 1997.

KOZMA, C. M.; REEDER, C. E.; SCHULZ, R. M.. Economic, clinical and humanistic outcomes: a planning model for pharmacoeconomics research. Clinical Therapy, v. 15, n. 6, p. $1121-1132.1993$.

KRAUSS-SILVA, L.. Avaliação tecnológica e análise custo-efetividade em saúde: a incorporação de tecnologias e a produção de diretrizes clínicas para o SUS. Ciência \& Saúde Coletiva, v. 8, n. 2, p. 501-520. 2003.

KRAUSS-SILVA, L.. Avaliação tecnológica em saúde: questões metodológicas e operacionais. Cadernos de Saúde Pública, v. 20, n. 2, p. S199-S207. 2004.

LA PLANTE, M. P.; HARRINGTON, C.; KANG, T.. Estimating paid and unpaid hours of personal assistance services in activities of daily living provided to adults living at home. Health Services Research, v. 37, n. 2, p. 397-415. 2002.

LAKATOS, E. M.; MARCONI, M. A.. Metodologia do trabalho científico. 4. ed. São Paulo: Atlas; 1997. 216p..

LAZAROU, J.; POMERANZ, B. H.; COREY, P. N.. Incidence of adverse drug reactions in hospitalized patients: a metaanalysis of prospective studies. Journal of American Medical Association, v. 279, p. 1200-1205. 1998.

LE GRAND, A.; HOGERZEIL, H. V.; HAAIJER-RUSKAMP, F. M.. Intervention in rational use of drugs: a review. Health Policy and Planning, v. 14, n. 2, p. 89-102. 1999.

LEE, M. P.; RAY, M. D.. Planning for pharmaceutical care. American Journal of Hospital Pharmacy, v. 50, p. 1153-1158. 1993.

LIMA, J. C.. Tradução para o português e validação do questionário específico para avaliação da qualidade de vida, em hipertensos de Bullpit e Fletcher. 2002. 144 f. Dissertação (Mestrado). Escola de Enfermagem de São Paulo, Universidade de São Paulo, São Paulo, 2002.

LIPTON, H. L.; BYRNS, P. J.; SOUMERAI, S. B.; CHRISCHILLES, E. A.. Pharmacists as agents of change for rational drug therapy. International Journal of Technology Assessment Health Care, v. 11, n.3, p. 485-508. 1995. 
LLIMÓS, F. F.. La información sobre medicamentos para la farmacia comunitaria. Pharmaceutical Care España, v. 1, n. 2, p. 90-96, mar./abr. 1999.

LLIMÓS, F. F.; ROMERO, F. M.; FAUS, M. J.. Problemas relacionados con la medicación: conceptos y sistemática de clasificación. Pharmaceutical Care España, v. 1, p. 279-288. 1999.

LLIMÓS, F. F.; FAUS, M. J.. Importance of medicine-related problems as risk factors. The Lancet, v. 362, n. 11, p. 1239, Oct. 2003.

LYRA JÚNIOR, D. P.. Impacto de um programa de atenção farmacêutica, nos resultados clínicos e humanísticos de um grupo de idosos, assistidos na unidade básica distrital de saúde Dr. Ítalo Baruffi, Ribeirão Preto (SP). 2005. 192 f. Tese (Doutorado em Ciências Farmacêuticas). Universidade de São Paulo. Ribeirão Preto, 2005.

MALEK, M.. Current principles and application of pharmacoeconomics. PharmacoEconomics, v. 9, n. 1, p. 1-8. 1996.

MALHOTRA, S.; JAIN, S.; PANDHI, P.. Drug-related visits to the medical emergency department: a prospective study from India. International Journal of Clinical Pharmacology and Therapeutics, v. 39, n. 1, p. 12-18. 2001.

MARIN, N.; LUIZA, V. L.; CASTRO, C. G. S. O.; SANTOS, S. M. (orgs). Assistência farmacêutica para gerentes municipais. Rio de Janeiro: OPAS/OMS; 2003. 373p..

MARTINS, D. S.. Custeio hospitalar por atividades: activity based costing. São Paulo: Atlas; 2002. 176 p..

MC ISAAC, W.; NAYLOR, C. D.; ANDERSON, G. M.; O'BRIEN, B. J.. Reflections on a month in the life of the Ontario drug benefit plan. Canadian Medical Association Journal, v. 150, p. 473-477. 1994.

MÉDICI, A. C.. Financiamento e contenção de custos nas políticas de saúde: tendências atuais e perspectivas futuras. Revista Planejamento e Políticas Públicas, v. 4, p. 83-98. 1990.

MENEZES, E. B. B.. Atenção farmacêutica em xeque. Infarma, v. 3, n. 22, p. 28, set./out. 2000.

MESTRINER, D. C. P.. O farmacêutico no serviço público de saúde: a experiência do município de Ribeirão Preto-SP. 2003. 134 f. Dissertação (Mestrado em Ciências Médicas). Universidade de São Paulo. Ribeirão Preto, 2003

MINISTÉRIO DA SAÚDE. Política Nacional de Medicamentos. Brasília: MS; 2001. 40 p. (Série C. Projetos, Programas e Relatórios, n. 25). 
MINISTÉRIO DA SAÚDE. Agenda nacional de prioridades de pesquisas em saúde: avaliação de tecnologias e economia da saúde. Brasília: Departamento de Ciências e Tecnologia. Secretaria de Ciência, Tecnologia e Insumos Estratégicos MS; 2004. 86 p..

MOORE, N.; LECOINTRE, D.; NOBLET, C.; MABILLE, M.. Frequency and cost of adverse drug reactions in a department of general medicine. Bristol Journal of Clinical Pharmacology, v. 45, p. 301-308. 1998.

MORRIS, C. J.; CANTRILL, J. A.; HEPLER, C. D.; NOYCE, P. R.. Preventing drug related morbidity: determining valid indicators. International Journal for Quality in Health Care, v. 14, n.3, p. 183-198. 2002.

MOSEGUI, G. B. G.. Custo social de tratamentos farmacológicos: uma proposta de modelo. 2002. 160 f. Tese (Doutorado em Saúde Coletiva), Universidade do Estado do Rio de Janeiro, Rio de Janeiro, 2002.

MOTA, D. M.. Avaliação farmacoeconômica: instrumentos de medida dos benefícios na atenção farmacêutica. Acta Farmacêutica Bonaerense, v. 22, n. 1, p. 73-80. 2003.

MOTA, D. M.; FERNANDES, M. E. P.; COELHO, H. L. L.. Farmacoeconomia: um instrumento de eficiência para a política de medicamentos do Brasil. Acta Farmacêutica Bonaerense, v. 22, n. 2, p. 177-186. 2003.

NAKAGAWA, M.. ABC: Custeio baseado em atividades. São Paulo: Atlas; 1994. 398 p..

NÄRHI, U.; AIRAKSINEN, M.; TANSKANEN, P.; ERLUND, H.. Therapeutic outcomes monitoring by community pharmacists for improving clinical outcomes in asthma. Journal of Clinical of Pharmacy and Therapeutics, v. 25, n. 3, p. 177-183, Jun. 2000.

NOVAES, H. M. D.. Avaliação de programas, serviços e tecnologias em saúde. Revista de Saúde Pública, v. 34, n. 5, p. 547-559. 2000.

O'BRIEN, J. M.. How nurse practitioners obtained provider status: lessons for pharmacists. American Journal Health System Pharmacy, v.60, n.22, p.23012307, Nov. 2003.

ODEGARD, P.S.; GOO, A.; HUMMEL, J.; WILLIAMS, K. L.; GRAY, S; L.. Caring for poorly controlled diabetes mellitus: a randomized pharmacist intervention. Annals of Pharmacotherapy, v. 39, n.3, p. 433-440, Mar. 2005.

OLSEN, J. A.; SMITH, R. D.; HARRIS, A.. Economic theory and the monetary valuation of health care: an overview of the issues as applied to the economic evaluation of health care programs. Working Paper 82, Victoria (Australia): Centre for Health Program Evaluation, Apr. 1999. 
OLSSON, J.; PERSSON, U.; TOLLIN, C.; NILSSON, S.; MELANDER, A.. Comparison of excess costs of care and production losses because of morbidity in diabetic patients. Diabetes Care, v. 17, n. 11, p. 1257-1263, Nov. 1994.

ORGANIZAÇÃO MUNDIAL DE SAÚDE (OMS). El papel del farmacéutico en la atención a la salud: declaración de Tokio. Genebra, Suiça: OMS; 1988. 41 p..

ORGANIZAÇÃO PANAMERICANA DE SAÚDE (OPAS). Consenso brasileiro de atenção farmacêutica: proposta. Brasília: OPAS; 2002a. 24 p..

ORGANIZAÇÃO PANAMERICANA DE SAÚDE (OPAS). Atenção farmacêutica no Brasil: trilhando caminhos. Brasília: OPAS; 2002b. 46 p. (relatório 2001-2002).

ORGANIZAÇÃO PANAMERICANA DE SAÚDE/ORGANIZAÇÃO MUNDIAL DE SAÚDE (OPAS/OMS). Guía para el desarrollo de servicios farmacéuticos hospitalarios: atención farmacéutica al paciente ambulatorio. Washington DC, EUA: OPAS/OMS; 1997. 19 p..

PANEL DE CONSENSO. Consenso de Granada sobre problemas relacionados con la medicación: conceptos y sistemática de clasificación. Pharmaceutical Care España, v. 1, n. 2, p. 107-112. 1999.

PANEL DE CONSENSO. Segundo consenso de Granada sobre problemas relacionados con la medicación. Ars Pharmaceutica, v. 43, n. 3-4, p. 175-184. 2002.

PASHOS, C. L.; KLEIN, E. G.; WANKE, L. A.. ISPOR Lexicon. Princeton, EUA: International society for pharmacoeconomic and outcomes research; 1998. 125 p..

PASSOS, A. D. C.; RUFFINO-NETTO, A.. Introdução aos estudos epidemiológicos analíticos. In: FRANCO, L. J.; PASSOS, A. D. C. (orgs). Fundamentos de epidemiologia. Barueri: Manole; 2005a. Cap. 11, p. 203-210.

PASSOS, A. D. C.; RUFFINO-NETTO, A.. Estudos experimentais. In: FRANCO, L. J.; PASSOS, A. D. C. (orgs). Fundamentos de epidemiologia. Barueri: Manole; 2005b. Cap. 12, p. 211-224.

PASSOS, A. D. C.; RUFFINO-NETTO, A.. Estudos de coorte. In: FRANCO, L. J.; PASSOS, A. D. C. (orgs). Fundamentos de epidemiologia. Barueri: Manole; 2005c. Cap. 13, p. 225-240.

PASSOS, A. D. C.; RUFFINO-NETTO, A.. Estudos de caso-controle. In: FRANCO, L. J.; PASSOS, A. D. C. (orgs). Fundamentos de epidemiologia. Barueri: Manole; 2005d. Cap. 14, p. 241-258.

PATEL, P.; ZED, P. J.. Drug-related visits to the emergency department: how big is the problem? Pharmacotherapy, v. 22, n. 7, p. 915-923. 2002. 
PEPE, V. L. E.; CASTRO, C. G. S.. A interação entre prescritores, dispensadores e pacientes: informação compartilhada como possível benefício terapêutico. Cadernos de Saúde Pública, v. 16, n. 3, p. 815-822, jul./set. 2000.

PEREIRA, M. G.. Epidemiologia: teoria e prática. Rio de Janeiro: Guanabara Koogan; 1995a. 596p..

PEREIRA, J.. Glossário de economia da saúde. In: Piola, S F; Vianna, S M.. Economia da saúde: conceito e contribuição para a gestão da saúde. 3. ed. Brasília: IPEA; 1995b. Apêndice, p. 271-293.

PEREIRA, L. R. L.; FREITAS, O.. Evolução da atenção farmacêutica no Brasil e no mundo: perspectiva para o Brasil. Revista Brasileira de Ciências Farmacêuticas, 2007. No prelo.

PHILLIPS, S. L.; CARR-LOPEZ, S. M.. Impact of a pharmacist on medications discontinuation in a hospital-based geriatric clinic. American Journal of Hospital Pharmacy, v. 47, p. 1075-1079. 1990.

PIRMOHAMED, M.; BRECKENRIDGE, A. M.; KITTERINGHAM, N. R.; PARK, B. K.. Adverse drug reactions. Bristol Medical Journal, v. 316, p. 1295-1298. 1998.

PLUMRIDGE, R. J.; WOJNAR-HORTON, R. E.. A review of the pharmacoeconomics of pharmaceutical care. PharmacoEconomics, v. 14, n. 2, p. 175-189. 1998.

POSEY, M.. Pharmaceutical care: will pharmacy incorporate its philosophy of practice? Journal of American Pharmaceutical Association, v. N537, n. 2, p. 145148. 1997.

PRADES, J. L. P.. Métodos de evaluación económica en salud publica. In: Navarro, F. M. et al. (eds). Salud pública. Madri: McGraw-Hill; 1998. p. 303-316.

REY, L.. Planejar e redigir trabalhos científicos. São Paulo: Edgar Blücher; 1987. 238p..

ROBINSON, R.. Economic evaluation and health care: what does it mean? British Medical Journal, v. 307, p. 670-673. 1993.

ROMANO-LIEBER, N. S.; TEIXEIRA, J. J. V.; FARHAT, F. C. L. G.; RIBEIRO, E.; CROZATTI, M. T. L.; OLIVEIRA, G. S. A.. Revisão dos estudos de intervenção do farmacêutico no uso de medicamentos por pacientes idosos. Cadernos de Saúde Pública, v. 18, n. 6, p.1499-1507, nov./dez. 2002.

ROTHMAN, K. J.; GREENLAND, S.. Modern Epidemiology. Washington: Lippincott-Raven; 1998. 738p.. 
ROUGHEAD, E. E.; GILBERT, A.L.; PRIMROSE, J.G.; SANSOM, L. N.. Drug related hospital admissions: a review of Australian studies published 1988-1996. The Medical Journal of Australia, v. 168, n. 8, p. 405-408. Apr. 1998.

ROZENFELD, S.. Avaliação do uso dos medicamentos como estratégia para a reorientação da política de insumos em saúde. Cadernos de Saúde Pública, v. 5, n. 4, p. 388-402. out./dez. 1989.

RUFFINO-NETTO, A.; PASSOS, A. D. C.. Epidemiologia: conceitos e usos. In: FRANCO, L. J.; PASSOS, A. D. C. (orgs). Fundamentos de epidemiologia. Barueri: Manole; 2005. Cap. 2, p. 29-46.

SAES, S. G.. Estudo bibliométrico das publicações em economia da saúde, no Brasil, 1989 - 1998. 2000. 104 f. Dissertação (Mestrado em Saúde Pública). Universidade de São Paulo, São Paulo, 2000.

SALA, A.. Avaliação de programas de saúde. In: Pereira, M. G. Epidemiologogia: teoria e prática. Rio de Janeiro: Guanabara-Koogan; 1997. Cap.24, p.527-538.

SALVIA, P. L.; MARÍ, A. A.; CHUST, V. S.; MARTÍNEZ, R. C.. Actuación farmacoterapéutica en el marco de un programa de atención farmacéutica. Revista OFIL, v. 9, p. 40-59. 1999.

SANTANA, E. M.. Avaliação econômica do programa de Saúde da Família (PSF) em municípios do estado da Bahia: um estudo de custos. Salvador: UFBA/ISC 2003. 107 p. (relatório de pesquisa - acordo de cooperação técnica Brasil-Reino Unido, MS/IPEA/DFID).

SCHMIDT, M. I.; DUNCAN, B. B.. Epidemiologia clínica e medicina baseada em evidências. In ROUQUAYROL, M. Z.; ALMEIDA FILHO, N.. Epidemiologia e saúde. 6. ed. Rio de Janeiro: Medsi; 2003. Cap. 8. p. 193-227.

SCHNEIDER, P. J.; GIFT, M. E.; LEE, Y. P.. Cost of medication-related problems at a university hospital. American Journal of Health System Pharmacy, v. 52, p. 2415-2418. 1995.

SECOLI, S. R.; PADILHA, K. G.; LITVOC, J.; MAEDA, S. T.. Farmacoeconomia: perspectiva emergente no processo de tomada de decisão. Ciência \& Saúde Coletiva, v. 10, p. 287-296. 2005.

SHELDON, T. A.. Problems of using modeling in the economic evaluation of health care. Journal of Health Economics, v. 5, p. 1-11. 1996.

SILVA, L. M. V.; FORMIGLI, V. L.. Avaliação em saúde: limites e perspectivas. Cadernos de Saúde Pública, v. 10, n. 1, p. 80-91, jan./mar. 1994. 
SILVA, M. G. C.. Economia da saúde: da epidemiologia à tomada de decisão. In ROUQUAYROL, M. Z.; ALMEIDA FILHO, N.. Epidemiologia e saúde. 6. ed. Rio de Janeiro: Medsi; 2003a. Cap.18. p. 533-565.

SILVA, R. R.. Acreditação de farmácias: a construção de um modelo. 2003. 197 f. Tese (Doutorado). Faculdade de Saúde Pública, Universidade de São Paulo, São Paulo, 2003b.

SILVA, S. H.; FERNANDES, R. A. Q.; GONÇALVES, V. L. M. A.. A administração de recursos materiais: importância do enfoque de custos e a responsabilidade dos profissionais de saúde. Revista Brasileira de Enfermagem, v. 47, n. 2, p. 160-164, abr./jun. 1994.

SIMON, G.; WAGNER, E.; VONKORFF, M.. Cost-effectiveness comparisons using "real world" randomized trials: the case of new antidepressant drugs. Journal of Clinical Epidemiology, v. 48, p. 363-373. 1995.

SINITOX - Sistema Nacional de Informações Tóxico-Farmacológicas. Estatística anual de casos de intoxicação e envenenamento: Brasil, 1999. Rio de janeiro: Fundação Oswaldo Cruzl Centro de Informação Científica e Tecnológica; 2000.

SMITH, C. C.; BENNETT, P. M.; PEARCE, H. M.; HARRISON, P. I.; REYNOLDS, D. J.; ARONSON, J. K. et al.. Adverse drug reactions in a hospital general medical unit meriting notification to committee on safety of medicines. Bristol Journal of Clinical Pharmacology, v. 42, p. 423-429. 1996.

SOARES, J. C. R. S.. Reflexões sobre a eficácia dos medicamentos na biomedicina. Cadernos de Saúde Coletiva, v. 6, p. 37-53. 1998.

SOCIEDADE BRASILEIRA DE VIGILÂNCIA DE MEDICAMENTOS (SOBRAVIME) e ACCIÓN INTERNACIONAL PARA LA SALUD (AIS) - América Latina y el Caribe. O que é uso racional do medicamento? São Paulo: SOBRAVIME; 2001. 128 p..

SOLOMON, D. K.; PORTNER, T. S.; BASS, G. E.; GOURLEY, D. R.; GOURLEY, G. A.; HOLT, J. M.; WICKE, W. R.; BRADEN, R. L.; EBERLE, T. N.; SELF, T. H.; LAWRENCE, B. L.. Clinical and economic outcomes in the hypertension and COPD arms of a multicenter outcomes study. Journal of the American Pharmaceutical Association, v.38, n.5, p.574-585, Sep./Oct. 1998.

SOLUÇÃO. Comunicação para profissionais envolvidos na distribuição de antiretrovirais. Saber Viver. n. 6, ano 1, mar./abr. 2005.

STORPIRTIS, S.; RIBEIRO, E.; MARCOLONGO, R.. Novas diretrizes para assistência farmacêutica hospitalar: Atenção Farmacêutica/Farmácia Clínica. In: GOMES, M. J. V. M.; REIS, A. M. M. Ciências farmacêuticas: uma abordagem em farmácia hospitalar. São Paulo: Atheneu; 2001. Cap. 29, p. 521-533. 
STRAND, L. M.. Re-visioning the profession. Journal of American Pharmaceutical Association, v. NS37, n. 4, p. 474-478, Jul./Aug. 1997.

STRAND, L. M.; CIPOLLE, R. J.; MORLEY, P. C.. Documenting the clinical pharmacist's activities: back to basics. Drug Intelligence \& Clinical Pharmacy, v. 22, n. 1, p. 63-67, Jan. 1988.

STRAND, L. M.; CIPOLLE, R. J.; MORLEY, P. C.; FRAKES, M. J.. The impact of pharmaceutical care practice on the practitioner and the patient in the ambulatory practice setting: twenty five years of experience. Current Pharmaceutical Design, v. 10, p. 3987-4001. 2004.

SULLIVAN, S. D.. Cost and cost-effectiveness in asthma: use of pharmacoeconomics to assess the value of asthma interventions. Immunology and Allergy Clinics of North America, v. 16, n. 4. p. 819-839. 1996.

TANAKA, O. Y.; MELO, C.. Uma proposta de abordagem transdisciplinar para avaliação em saúde. Interface - Comunicação em Saúde, v. 7, p. 113-118, ago. 2000.

TANAKA, O. Y.; MELO, C.. Avaliação de programas de saúde do adolescente: um modo de fazer. São Paulo: EDUSP; 2004. 83 p..

TIMBS, O.. Leading role for pharmacists to reduce drug errors and improve patient safety. The Pharmaceutical Journal, v. 268, p. 392, mar. 2002.

TOLEDO, F. A.; GONZÁlEZ, P. A.; RIERA, T. E.; FERRER, F. F. A.; MARTÍNEZ, A. D.; MIRAGAYA, L. C.; POSADA. I. S.; SÁNCHEZ, G. A.. Atención farmacéutica en personas que han sufrido episodios coronarios agudos (estudio TOMCOR). Revista Española de Salud Pública, v.75, n. 4, p.375-387, jul./ago. 2001.

TOMECHKO, M. A.; MORLEY, P. C.; STRAND, L. M.. Comprehensive pharmaceutical care: an overview of an evolving practice model. Journal of Pharmacy Teaching, v.5, n.1/2, p.73-84, Jan./Apr. 1996.

TORRANCE, G. W.. Measurement of health state utilities for economic appraisal. Journal of Health Economics, v. 5, p. 1-30. 1986.

UGÁ, M. A. D.. Instrumentos de avaliação econômica dos serviços de saúde: alcances e limitações. In: Piola, S F; Vianna, S M.. Economia da saúde: conceito e contribuição para a gestão da saúde. 3. ed. Brasília: IPEA; 1995. Cap.IX, p. 209-226.

VELÁSQUEZ, G.. Farmacoeconomia: evaluación científica o estrategia comercial. Revista Panamericana de Salud Pública, v. 5, n.1, p. 54-57. 1999. 
VIACAVA, F.; ALMEIDA, C.; CAETANO, R.; FAUSTO, M.; MACINKO, J.; MARTINS, M.; NORONHA, J. C.; NOVAES, H. M. D.; OLIVEIRA, E. S.; PORTO, S. M.; SILVA, L. M. V.; SZWARCWALD, C. L.. Uma metodologia de avaliação do desempenho do sistema de saúde brasileiro. Ciência \& Saúde Coletiva, v. 9, n. 3, p. 711-724. 2004.

VIANNA, D.; MESQUITA, E. T.. Economia da saúde: ferramenta para a tomada de decisão em medicina. Revista da SOCERJ, v. 16, n. 4, p. 258-261. out./nov./dez. 2003.

VIEIRA, E. M.. Avaliação de serviços de saúde. In: FRANCO, L. J.; PASSOS, A. D. C. (orgs). Fundamentos de epidemiologia. Barueri: Manole; 2005. Cap. 20, p. 337354.

VIEIRA, F. S.. Possibilidades de contribuição do farmacêutico para a promoção da saúde. Ciência \& Saúde Coletiva, v. 12, n. 1, p. 213-220. 2007.

VILLAR, F. A.. Evaluación económica aplicada a los medicamentos: características y metodología. In: DEL CASTILHO, J. A. S.; LLACH, X. B.; ROVIRA, J.. Farmacoeconomia: evaluación económica de los medicamentos. Madri, Espanha: Medica; 1995. p. 31- 50.

VILLAR, F. A.. Economía y salud. Conceptos básicos. Eficacia y eficiencia. La evaluación económica de tecnologías sanitarias. Características y metodología. In: JIMÉNEZ. J.. Manual de gestión para jefes de servicios clínicos. 2. ed. Madri, Espanha: Diaz de Santos. 2000.

WALLEY, T.; HAYCOX, A.. PharmacoEconomics: basic concepts and terminology. Bristol Journal of Clinical Pharmacology, v. 43, p. 343-348. 1997.

WEIDLE, P., BRADLEY, L., GALLINA, J.; MULLINS, C. D.; THORN, D.; SEIGEL, L. P.. Pharmaceutical care intervention documentation program and related cost savings at a university hospital. Hospital Pharmacy, v. 34, n. 1, p. 43-52. 1999.

WEINSTEIN, M. C.; MANNING JUNIOR, W.. Theoretical issues in cost-effectiveness analysis. Journal of Health Economics, v. 16, p. 121-128. 1997.

WHITE, T. J.; ARAKELIAN, A.; RHO, J. P.. Counting the costs of the drug-related adverse events. PharmacoEconomics, v. 15, n. 5, p. 445-458, 1999.

Winterstein, A. G.; SAUER, B. C.; HEPleR, C. D.; POOLE, C.. Preventable drug-related hospital admission. Annals of Pharmacotherapy, v. 36, n. 7, p. 12381248. 2002.

ZANINI, A. C.; FARHAT, F. C. L. G.; RIBEIRO, E.; FOLLADOR, W.. Farmacoeconomia: conceitos e aspectos operacionais. Revista Brasileira de Ciências Farmacêuticas, v. 37, n. 3, p. 225-237, set./dez. 2001. 
ZUCCHI, P.. Gastos em saúde: os fatores que agem na demanda e na oferta de serviços de saúde. 1995. 101 f. Dissertação (Mestrado em Administração de Empresas), Fundação Getúlio Vargas, São Paulo, 1995. 